Check for updates

Cite this: Mater. Adv., 2021, 2, 3405

Received 25th September 2020, Accepted 31st March 2021

DOI: $10.1039 / \mathrm{d} 0 \mathrm{ma00737d}$

rsc.li/materials-advances

\title{
Development of $\mathrm{LiMgBO}_{3}: \mathrm{Tb}^{3+}$ as a new generation material for thermoluminescence based personnel neutron dosimetry $\dagger$
}

\author{
Meghnath Sen, ${ }^{\text {ab }}$ Rakesh Shukla, ${ }^{c}$ Nimai Pathak, ${ }^{\text {bd }}$ Kaustava Bhattacharyya, (D) bc \\ V. Sathian, ${ }^{a}$ Probal Chaudhury, ${ }^{a b}$ Mukund S. Kulkarni ${ }^{\text {be }}$ and Avesh K. Tyagi iD *bc
}

\begin{abstract}
Personnel neutron dosimetry is of utmost importance due to high relative biological effectiveness (RBE) of neutrons compared with other ionizing radiation. Thermoluminescence (TL) is one of the most widely used techniques in this vital application where LiF:Mg,Ti is recognized as the benchmark material used world-over. However, its complex TL glow curve, complicated treatment procedure and loss of sensitivity upon reuse demand the development of new and more efficient materials. The present work reports the systematic development of the $\mathrm{LiMgBO}_{3}: \mathrm{Tb}^{3+}$ phosphor for personnel neutron dosimetry applications along with detailed structural characterizations. The neutron irradiated TL study on $\mathrm{LiMgBO}_{3}: \mathrm{Tb}^{3+}$ reveals a simple TL glow curve compared with the very complex pattern of LiF:Mg,Ti. The $\mathrm{TL}$ sensitivity for neutrons and the $n / \gamma$ dose discrimination capability of $\mathrm{LiMgBO}_{3}: \mathrm{Tb}^{3+}$ is found to be 2.2 times and 4.5 times higher, respectively, compared with that of the standard material. Also, the TL response up to $105 \mathrm{mSv}$ of neutron dose shows excellent linearity and, most importantly, the fading of the TL signal even up to 90 days of storage is less than $10 \%$. These features meet the ISO-21909 criteria for the practical applicability of this material as a TL based personnel neutron dosimeter. The detailed Photoluminescence (PL) emission and lifetime along with Electron Paramagnetic resonance (EPR) studies were carried out to delineate the underlying TL behaviour through identifying different neutron induced defect centres. Moreover, the trap parameters have been calculated using different methods in order to understand the TL kinetics.
\end{abstract}

\section{Introduction}

Thermoluminescence (TL) is one of most widely used research techniques applied in several fields viz. persistent luminescence, band gap engineering, photosynthesis and, most importantly, radiation dosimetry etc. ${ }^{1-6}$ Among several types of ionizing radiation, the most important one is neutron radiation as it has the highest relative biological effectiveness (RBE) over other radiation types. TL has been successfully utilised over the years as one of the personnel neutron dosimetry techniques which, however, is very complex and poses great challenges. This is mainly because neutrons have a wide range of energy and their interaction cross section is highly dependent upon

\footnotetext{
${ }^{a}$ Radiation Safety Systems Division, Bhabha Atomic Research Centre, Mumbai400085, India

${ }^{b}$ Homi Bhabha National Institute, Anushaktinagar, Mumbai-40094, India ${ }^{c}$ Chemistry Division, Bhabha Atomic Research Centre, Mumbai-400085, India

${ }^{d}$ Radiochemistry Division, Bhabha Atomic Research Centre, Mumbai-400085, India

${ }^{e}$ Health Physics Division, Bhabha Atomic Research Centre, Mumbai-400085, India. E-mail: aktyagi@barc.gov.in; Tel: +0091-22-2559-5330

$\dagger$ Electronic supplementary information (ESI) available. See DOI: 10.1039/d0ma00737d
}

their energy. Moreover, the presence of gamma radiation along with neutrons in most workplaces makes the situation most critical. Considering these intricacies, so far, mainly LiF based materials have been used for this application. Doped LiF was reported for TL dosimetry applications by Cameron in $1961 .^{7}$ After that, the pair of TLD-600 ( $\left.{ }^{6} \mathrm{LiF}: \mathrm{Mg}, \mathrm{Ti}\right)$ and TLD-700 $\left({ }^{7} \mathrm{LiF}: \mathrm{Mg}\right.$,Ti) was successfully introduced for personnel neutron monitoring. ${ }^{8-10} \mathrm{LiF}: \mathrm{Mg}, \mathrm{Cu}, \mathrm{P}$ has also been studied for the said purpose by several researchers. ${ }^{11,12}$ However, these dosimeters suffer from many disadvantages, such as their complex glow curve structure, complicated annealing procedure, loss of sensitivity upon reuse and retention of the residual signals. ${ }^{13,14}$ Therefore, there is great scope for the development of new and more efficient materials for TL based personnel neutron dosimetry. Over the years, enormous research has been devoted towards borate based materials owing to their ease of preparation, large band gap and excellent luminescence efficiency. ${ }^{15}$ Considering these, several researchers in the recent past have worked specifically on the development of borate based TL materials as an alternative to the existing LiF:Mg,Ti neutron dosimeter. ${ }^{16-20}$ However, the majority of these studies lack systematic investigations 
viz. neutron dose linearity within the personnel dosimetry region, fading studies, minimum detectable dose measurements etc. and, most importantly, the physical understanding of the observed neutron induced TL behaviour. In view of the above, the present paper focused on the synthesis, detailed structural characterization and TL based personnel neutron dosimetry studies of the novel $\mathrm{LiMgBO}_{3}: \mathrm{Tb}^{3+}$ phosphor along with the in-depth understanding of the TL behaviour supported by neutron irradiated PL and EPR investigations. $\mathrm{LiMgBO}_{3}$ is one of the lightest candidates of the mixed metal borate family $\left(\mathrm{MM}^{\prime} \mathrm{BO}_{3}\right.$ where $\mathrm{M}=\mathrm{Li}, \mathrm{Na}, \mathrm{K} ; \mathrm{M}^{\prime}=\mathrm{Be}$, $\mathrm{Mg}$, $\mathrm{Ca}, \mathrm{Sr}$ and $\mathrm{Ba}$ ) where the main building block is a planar $\left[\mathrm{BO}_{3}\right]^{3-}$ unit which offers highly localized valence electrons, anisotropic polarizability, high optical quality and low wavelength absorption. ${ }^{21,22}$ These features have attracted researchers to study their detailed crystal structure and applications as deep UV NLO (non-linear optical) materials and in phosphor converted solid state lighting. ${ }^{23-26}$ The crystal structure of $\mathrm{LiMgBO}_{3}$ was first reported by Lehman et al. ${ }^{27}$ in 1962 . In the recent past, various researchers have reported un-doped or doped $\mathrm{LiMgBO}_{3}$ for its structural and electrical properties, luminescence properties, and applications as coloured chromophores and in red-light emitting diodes. ${ }^{28-32}$ However, although there are reports on the TL based dosimetry studies on $\mathrm{LiMgBO}_{3}$ for beta- and gammaradiation, its applications for neutron dosimetry have not been studied so far. ${ }^{33,34}$ Recently TL based personnel neutron dosimetry study was reported for $\mathrm{LiMgBO}_{3}: \mathrm{Dy}^{3+}$ but the low neutron sensitivity and high fading of this phosphor have limited its practical use. ${ }^{35}$ Therefore, aiming at better neutron dosimetry properties, and based on previous research experiences, the present paper investigated the novel $\mathrm{LiMgBO}_{3}: \mathrm{Tb}^{3+}$ phosphor (using the $\mathrm{Tb}^{3+}$ dopant instead of $\mathrm{Dy}^{3+}$ ) which not only overcomes the above-mentioned shortcomings but also provides very promising results which might become a potential alternative to the existing $\mathrm{LiF}: \mathrm{Mg}$,Ti dosimeter. ${ }^{36-38}$ The systematic basis for the selection of $\mathrm{LiMgBO}_{3}$ as the host material for TL based personnel neutron dosimetry has been discussed in detail in Text-S1 (ESI $\dagger$ ). On the other hand, the $\mathrm{Tb}^{3+}$ dopant was selected considering two major potent features: first, it is well known for its potential green light emission characteristics where the majority of photomultiplier tubes used in TL readers have very good sensitivity. ${ }^{39-41}$ Second, and most importantly, the $\mathrm{Tb}^{3+}$ dopant usually generates deep trap centres in the host materials giving rise to a reasonably high temperature and stable TL glow peak which is very desirable for luminescence based dosimetry applications. ${ }^{42,43} \mathrm{LiMgBO}_{3}: \mathrm{Tb}^{3+}$ was synthesized by the sol-gel method, and Rietveld refinement of the XRD pattern enabled to obtain the crystal structure of the compound. Diffuse Reflectance UV-visible (DRUV-vis) spectroscopy study revealed $\mathrm{LiMgBO}_{3}$ as a good insulator with a high optical band gap of $6.3 \mathrm{eV}$, an essential criterion for TL based dosimetry applications. Infra-red spectra (IR), SEM and EDS measurements were carried out to identify the functional groups, crystal morphology and the presence of constituent elements in the material, respectively. Photoluminescence (PL) study proved $\mathrm{LiMgBO}_{3}: \mathrm{Tb}^{3+}$ to be a potential green emitting phosphor from the emission characteristics of the $\mathrm{Tb}^{3+}$ dopant, which is also responsible for the glow curve in the TL study. PL lifetime studies of the un-irradiated samples explained the distribution of $\mathrm{Tb}^{3+}$ among different crystallographic sites whereas PL lifetime studies for neutron irradiated compounds were correlated (for the first time to the best of our knowledge) to the origin of the TL glow curve and their relative contributions towards the total TL intensity. The effect of neutron- and gamma-irradiation on the PL emission properties was also studied thoroughly. Electron Paramagnetic Resonance (EPR) study helped to understand the nature of defect centres generated upon irradiation with neutron- and gamma-radiation, based on which a possible mechanism for the $\mathrm{TL}$ emission of $\mathrm{LiMgBO}_{3}: \mathrm{Tb}^{3+}$ has been established. Additionally, various kinetic parameters viz. the activation energy $(E)$, frequency factor $(s)$ and order of kinetics $(b)$ responsible for the TL properties have been estimated with two different methodologies and the results were found to be in good agreement. Therefore, a combination of these studies on $\mathrm{LiMgBO}_{3}: \mathrm{Tb}^{3+}$ not only provides a new strategy towards the rational development of new TL materials for personnel neutron dosimetry applications but will also benefit greatly understanding the impact of neutron radiation on the photophysical properties of phosphor materials.

\section{Experimental section}

\subsection{Starting chemicals}

Lithium acetate di-hydrate $\left[\mathrm{CH}_{3} \mathrm{COOLi} \cdot 2 \mathrm{H}_{2} \mathrm{O}, \mathrm{AR}\right]$, magnesium nitrate hexa-hydrate $\left[\mathrm{Mg}\left(\mathrm{NO}_{3}\right)_{2} \cdot 6 \mathrm{H}_{2} \mathrm{O}, \mathrm{AR}\right]$ and boric acid $\left[\mathrm{H}_{3} \mathrm{BO}_{3}\right.$, 99.95\%]. Citric acid, $\mathrm{CA}\left[\mathrm{C}_{6} \mathrm{H}_{8} \mathrm{O}_{7}, \mathrm{AR}\right]$, ethylene glycol, EG $\left[\left(\mathrm{CH}_{2} \mathrm{OH}\right)_{2}, \mathrm{AR}\right]$, nitric acid $\left[\mathrm{HNO}_{3}, \mathrm{AR}\right]$, terbium oxide $\left[\mathrm{Tb}_{4} \mathrm{O}_{7}\right.$, 99.9\%], deionized $\mathrm{H}_{2} \mathrm{O}$.

\subsection{Synthesis}

Synthesis of the phosphor $\mathrm{LiMgBO}_{3}: x \mathrm{~Tb}^{3+}(x=0,0.01,0.02$, $0.03,0.04$ and $0.06 \mathrm{~mol}$ ) was carried out by sol-gel method. The stoichiometric amounts of $\mathrm{CH}_{3} \mathrm{COOLi} \cdot 2 \mathrm{H}_{2} \mathrm{O}$ and $\mathrm{Mg}\left(\mathrm{NO}_{3}\right)_{2}$. $6 \mathrm{H}_{2} \mathrm{O}$ were weighed and dissolved in slightly acidic deionised water in a beaker (here beaker no. 1). Required amount of $\mathrm{Tb}_{4} \mathrm{O}_{7}$ was dissolved in dil. $\mathrm{HNO}_{3}$ medium in beaker no. 2. In another beaker, no. 3 , an aqueous solution of $\mathrm{H}_{3} \mathrm{BO}_{3}$ was also prepared to the required concentration. All the stock solutions were kept overnight which resulted in clear solutions. After that, the $\mathrm{H}_{3} \mathrm{BO}_{3}$ and $\mathrm{Tb}_{4} \mathrm{O}_{7}$ solutions from beaker nos. 2 and 3 were poured into beaker 1 under continuous slow stirring. Beaker 1 was then allowed to boil slowly on the hotplate under continuous stirring. The temperature of the solution was kept fixed at $353 \mathrm{~K}$. Meanwhile, solution of the required amount of citric acid (CA) was also prepared in beaker no. 4. After that, CA and EG were added to the mixed metal nitrate (MN) solution in beaker 1 very slowly by keeping the MN : CA and MN : EG ratio at $1: 1$ and $1: 2$ respectively under continuous stirring. After a while, brown nitrous fumes emanated and a viscous gel was formed, which upon further heating produced a yellowish white coloured foamy product. It was then dried at $473 \mathrm{~K}$ for $6 \mathrm{~h}$, which gave rise to a very fine powder on crushing. Next, the powders were ground well using a grey agate mortar and pestle before being transferred into an alumina boat. Calcination of 
the powder was done in three steps viz. at $723 \mathrm{~K}, 1073 \mathrm{~K}$ and $1123 \mathrm{~K}$, respectively for 6 hours (heating rate $5 \mathrm{~K} \mathrm{~min}^{-1}$ ) at each temperature, and in the final step a white colored compound was obtained. During the interval of each step, the intermediate product was ground thoroughly and then kept for heating at the next higher temperature. All products were then washed with hot de-ionized water to remove any boron oxide impurities. Last, the materials were annealed at $573 \mathrm{~K}$ for $30 \mathrm{~min}$ before conducting the characterizations.

\subsection{Instrumentation and irradiation details}

The phase pure formation of the synthesized materials was characterized by powder X-Ray diffraction (XRD) using monochromatic $\mathrm{Cu}-\mathrm{K}_{\alpha}$ radiation $(\lambda=1.5406 \AA)$ on a Rigaku smart lab diffractometer. An SNE4500 instrument was used to record the SEM micrographs. A Bruker Nano GmbHX Flash detector 410M (Berlin, Germany) was used for recording the EDS spectrum. UV-visible measurements were carried out on a two-beam spectrometer (V-670, JASCO) with a diffuse reflectance (DR) attachment having an integration sphere coated with barium sulphate $\left(\mathrm{BaSO}_{4}\right)$ as a reference. A Nicolet (Madison, WI, USA) 6700 FTIR spectrometer equipped with both mercury cadmium telluride (MCT) and DTGS (Deuterated Triglycine Sulphate) detectors was used to record the FT-IR spectra. PL measurements were carried out using an Edinburgh CD-920 unit with M 300 monochromators. F-900 software from Edinburgh Analytical Instruments, UK was used for data analysis. A Xenon flash with a frequency of $100 \mathrm{~Hz}$ was utilized to record the emission spectra. The PL lifetime measurements were carried out based on the Time-correlated Single-Photon Counting (TCSPC) technique. EPR experiments were carried out using a Bruker EMX (micro) 10/12 spectrometer operating at X-band frequency $(9.4218 \mathrm{GHz})$ equipped with $100 \mathrm{kHz}$ field modulation and phase sensitive detection. Diphenyl picrylhydrazyl (DPPH) was used for calibration of $g$-values of the paramagnetic species. A lexsyg smart automatic TL/OSL reader, Freiberg, Germany was used to measure all the thermoluminescence (TL) data using an IRSL-TL filter (Schott-BG39-3 mm). The reader used a standard bi-alkali cathode PMT (HAMAMATSU). All the neutron irradiations were carried out at the Standard thermal Assembly in Graphite [STAG] facility which is a primary standard for the thermal neutron fluence rate. Six ${ }^{241} \mathrm{Am}$ Be neutron sources were kept inside a cubic assembly made of graphite. Thermal neutrons are produced by the moderation of fast neutrons through interaction with graphite. Irradiation with gamma rays during sensitivity comparisons was carried out using $\mathrm{a}^{60} \mathrm{Co}$ source from Co-machine (Theratron 780E, Kirloskar), RSSD, BARC. The distance between the centre of the source and the sample was 1 meter. The samples were sandwiched between two build up sheets $(6 \mathrm{~mm}$ thick sheet in the front side facing the radiation and $20 \mathrm{~mm}$ thick sheet in the back side) made of perspex. The activity of the source was $4181 \mathrm{Ci}$ as on the date of experiment and the field size was $10 \mathrm{~mm} \times 10 \mathrm{~mm}$. For EPR studies the irradiation with gamma rays (dose $=8.2 \mathrm{kGy}$ ) was performed in gamma chamber-1200 (Board of Radiation and Isotope Technology, Mumbai, India) where ${ }^{60} \mathrm{Co}$ was used as the

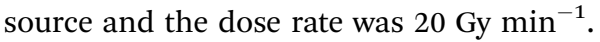

\section{Results and discussion}

\subsection{Structural characterization}

3.1.1 XRD, SEM, EDS and IR studies. The phase pure formation of all the compositions of $\mathrm{LiMgBO}_{3}: x \mathrm{~Tb}^{3+}(x=0$, $0.01,0.02,0.03,0.04$ and $0.06 \mathrm{~mol}$ ) was confirmed by powder XRD patterns which matched very well with the standard JCPDS file no. 79-1996 as shown in Fig. 1. The sharp diffraction peaks indicate good crystallinity of the synthesized powders. In order to obtain the crystal structure, the Rietveld refinement of the powder XRD pattern of $\mathrm{LiMgBO}_{3}$ was carried out using Full-prof 2000 software as shown in Fig. 2. ${ }^{44}$ The schematic representation of the structure of $\mathrm{LiMgBO}_{3}$ in a ball-and-stick framework is depicted in Fig. S1 (ESI $\dagger$ ). The refined parameters and the crystal structure are also shown in Table 1 and Fig. 3, respectively. It was found that $\mathrm{LiMgBO}_{3}$ adopts a monoclinic crystal system with space group $C 2 / c$ and the structure is similar to that observed by $\mathrm{Wu}$ et al. ${ }^{32}$ The crystal structure indicates that the $\mathrm{Li}^{+}$ion occupies two

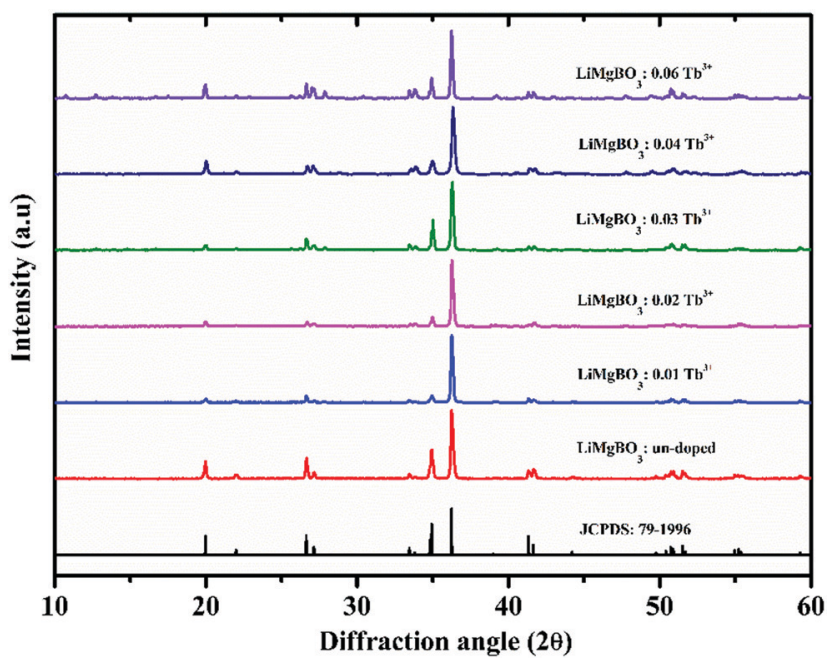

Fig. 1 Powder XRD pattern of different compositions of $\mathrm{LiMgBO}_{3}: \mathrm{Tb}^{3+}$.

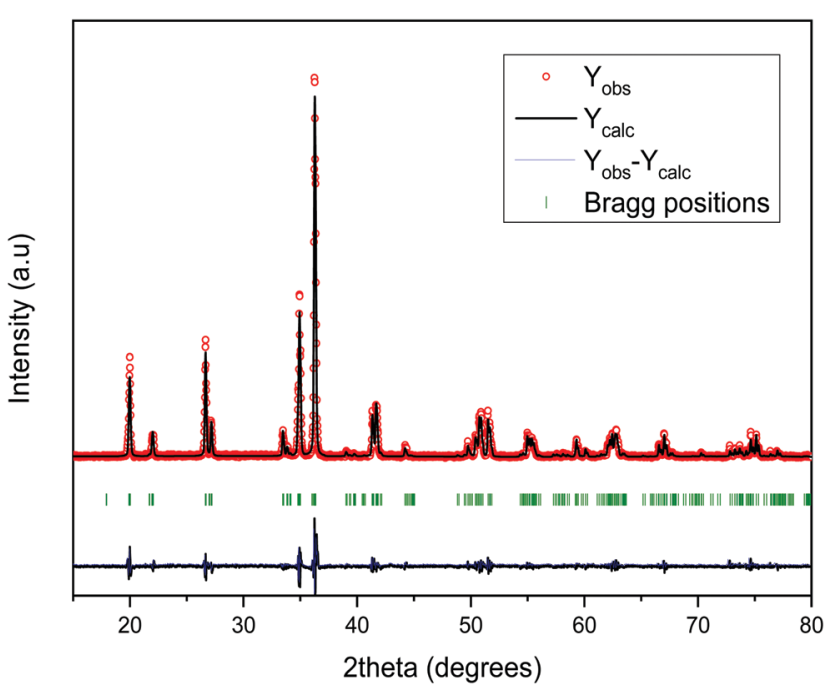

Fig. 2 Rietveld refinement of powder XRD pattern of $\mathrm{LiMgBO}_{3}$. 
Table 1 Different parameters of $\mathrm{LiMgBO}_{3}$ obtained from the Rietveld refinement

\begin{tabular}{ll}
\hline Molecular formula & $\mathrm{LiMgBO}_{3}$ \\
Molecular weight & 485.54 \\
Space group & $C 2 / c$ \\
Unit cell parameters: & \\
$a(\AA)$ & $5.1568(2)$ \\
$b(\AA)$ & $8.8858(4)$ \\
$c(\AA)$ & $9.9128(3)$ \\
$\beta\left({ }^{\circ}\right)$ & $91.236(3)$ \\
Volume $\left(\AA^{3}\right)$ & $454.12(3)$ \\
Density $($ calculated) $(\mathrm{g} / \mathrm{cc})$ & 2.63 \\
Refinement & Rietveld refinements (Fullprof-2K) \\
& (Rodriguez-Caravjal, 2000) \\
Profile & Pseudo-Voigt \\
Goodness-of-fit $\left(\chi^{2}\right)$ & 2.58 \\
$R_{\mathrm{p}}$ & 16.0 \\
$R_{\mathrm{wp}}$ & 20.8 \\
$R_{\mathrm{F}}$ & 11.6 \\
\end{tabular}

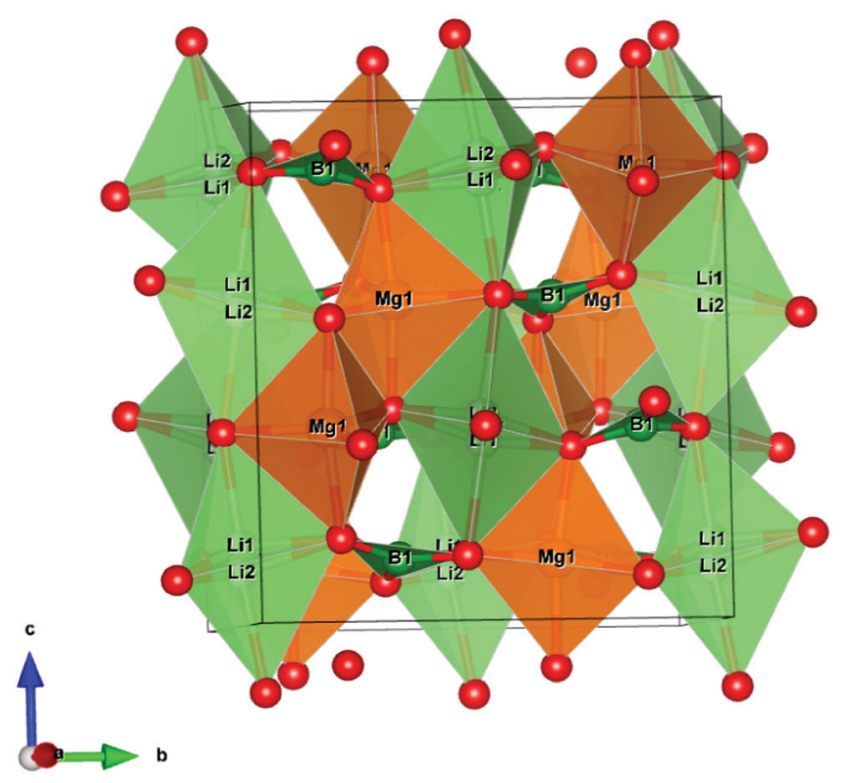

Fig. 3 The schematic polyhedral structure of $\mathrm{LiMgBO}_{3}$.

different crystallographic sites viz. $\mathrm{Li}$ (1) and $\mathrm{Li}$ (2) which are approximately $50 \%$ occupied with interatomic distance of $\sim 0.5 \AA$. Both the $\mathrm{Li}$ sites are five-fold coordinated by four close and a distant $\mathrm{O}$ atom forming a distorted trigonal bipyramid and which are connected via edge-sharing. $\mathrm{Mg}^{2+}$ occupies only one site in the structure and forms trigonal bipyramidal polyhedra [coordination number $(\mathrm{CN})=5$ ] with edge sharing in a zig-zag manner. The $\mathrm{MgO}_{5}$ bipyramids and $\mathrm{LiO}_{5}$ bipyramids share corners with the adjacent $\mathrm{BO}_{3}$ triangles. The ionic radii of $\mathrm{Li}^{+}, \mathrm{Mg}^{2+}$ and $\mathrm{Tb}^{3+}(\mathrm{CN}=$ 6) are $0.76 \AA 0.72 \AA$ and $0.92 \AA$ respectively. Based on the ionic radii and the charge difference between the dopant and the metal ions it was found that $\mathrm{Tb}^{3+}$ can prefer both the $\mathrm{Mg}^{2+}$ and $\mathrm{Li}^{+}$sites in the structure. However, site occupancy refinement studies pointed toward mixing of cations with a preference for the $\mathrm{Mg}^{2+}$ site over the $\mathrm{Li}^{+}$site in the $\mathrm{LiMgBO}_{3}$ lattice. These studies were found to be in agreement with the PL study as described in detail in Section 3.1.3.
In order to investigate the crystal size and surface morphology of the different compositions of $\mathrm{LiMgBO}_{3}: \mathrm{Tb}^{3+}$, Scanning Electron Microscopy (SEM) images were recorded as given in Fig. S2 (ESI $\dagger$ ). These revealed that the materials were microcrystalline in nature with irregular shapes. Energy Dispersive Spectroscopy (EDS) studies as shown in Fig. S3 (ESI $\dagger$ ) were carried out to investigate the elemental compositions in the matrix. The presence of $\mathrm{Mg}$ and $\mathrm{O}$ was confirmed by their characteristic peaks at $1.25 \mathrm{keV}$ and $0.52 \mathrm{keV}$, respectively. The inset curve shows the EDS pattern of un-doped and $\mathrm{Tb}^{3+}$ doped samples, which clearly indicated the characteristic Tb peak at $6.3 \mathrm{keV}$ in the doped sample whereas the same is absent for the un-doped material. Being low- $Z$ elements, $\mathrm{Li}$ and $\mathrm{B}$ could not be detected whereas the Gold (Au) peak was observed due to the coating of the samples. To characterize the coordination environment of the synthesized $\mathrm{LiMgBO}_{3}: \mathrm{Tb}^{3+}$, room temperature IR spectra were recorded as shown in Fig. 4.

The spectrum showed the presence of about 15 different active IR bands in the range $400-2000 \mathrm{~cm}^{-1}$, which matched very well with different modes as reported in the literature. ${ }^{45-48}$ The bands within 1000-1550 $\mathrm{cm}^{-1}\left(1213 \mathrm{~cm}^{-1}, 1268 \mathrm{~cm}^{-1}\right.$ and $1439 \mathrm{~cm}^{-1}$ and $1510 \mathrm{~cm}^{-1}$ ) were attributed to the asymmetric stretching vibrations of the $\mathrm{B}-\mathrm{O}$ bond in $\mathrm{BO}_{3}$ whereas, the band at $864 \mathrm{~cm}^{-1}$ is due to the symmetric stretching of the $\mathrm{B}-\mathrm{O}$ bond in $\mathrm{BO}_{3}$. The IR bands within $650-850 \mathrm{~cm}^{-1}\left(711 \mathrm{~cm}^{-1}, 723 \mathrm{~cm}^{-1}\right.$, $778 \mathrm{~cm}^{-1}$ and $800 \mathrm{~cm}^{-1}$ ) arise due to the out-of-plane bending vibrations of the B-O bond and those within $500-600 \mathrm{~cm}^{-1}$ $\left(530 \mathrm{~cm}^{-1}, 577 \mathrm{~cm}^{-1}\right.$ and $\left.651 \mathrm{~cm}^{-1}\right)$ correspond to the in-plane deformation modes of the $\mathrm{B}-\mathrm{O}$ bond. Based on these active bands it was confirmed that the triangular $\left[\mathrm{BO}_{3}\right]^{3-}$ group is present in the crystal environment which is one of the main building blocks of the material. ${ }^{49}$ Also, the bands at $420 \mathrm{~cm}^{-1}$ and $456 \mathrm{~cm}^{-1}$ refer to the $\mathrm{Mg}-\mathrm{O}$ and $\mathrm{Li}-\mathrm{O}$ bonds respectively.

3.1.2 Diffuse Reflectance UV-Visible spectroscopy (DRUV-vis) studies. The Diffuse Reflectance UV-Visible (DRUV) spectra of $\mathrm{LiMgBO}_{3}: x \mathrm{~Tb}^{3+}(x=0,0.01,0.04$ and 0.06$)$ are shown in Fig. 5. The spectral patterns are similar for all the compositions. The lower part of the spectra i.e., within 200-300 nm corresponds

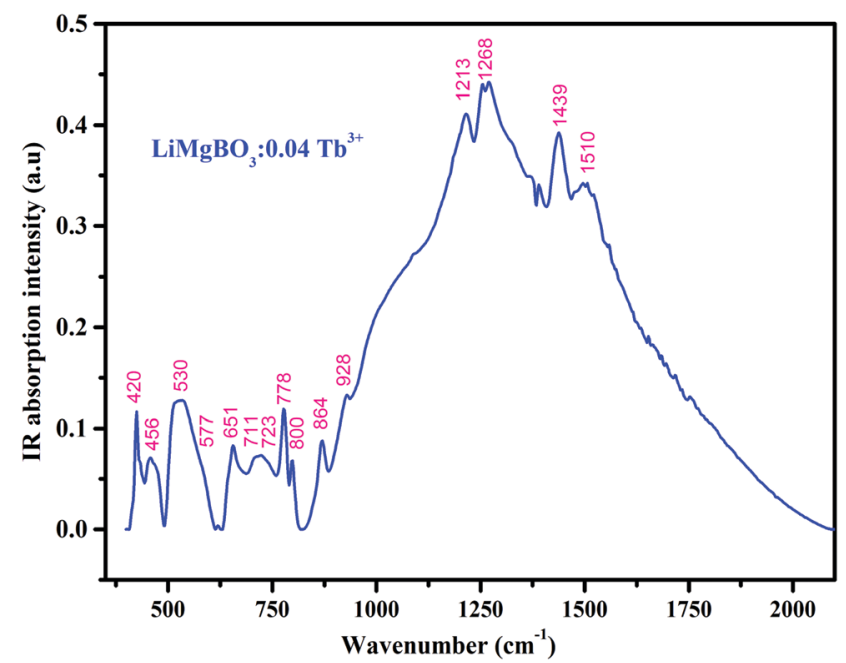

Fig. 4 Infra-red (IR) spectra of $\mathrm{LiMgBO}_{3}: 0.04 \mathrm{~Tb}^{3+}$. 


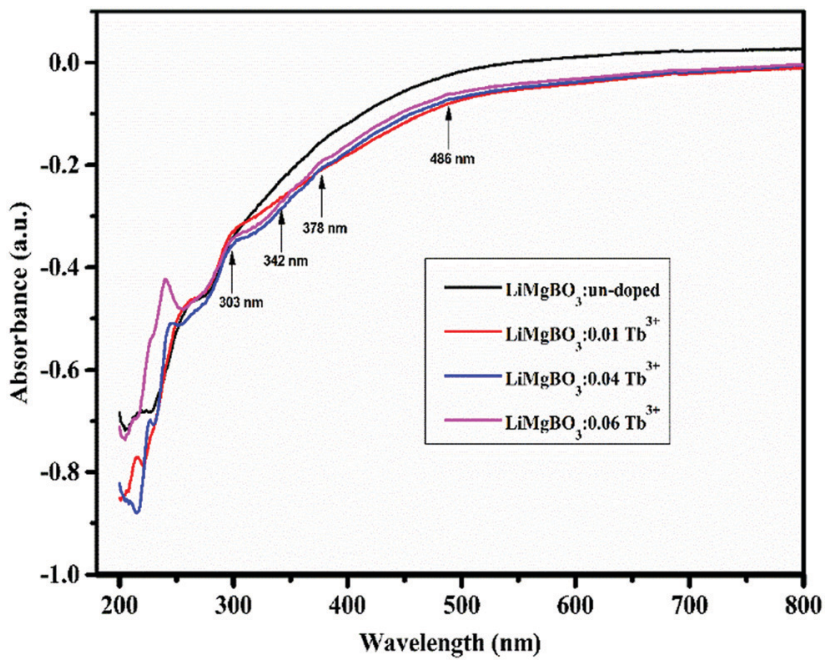

Fig. 5 Diffuse reflectance spectra (DRS) of $\mathrm{LiMgBO}_{3}: x \mathrm{~Tb}^{3+}(x=0,0.01$, 0.04 and 0.06 ).

to the host related absorption and beyond that the electronic transitions of the $\mathrm{Tb}^{3+}$ dopant were responsible for the peaks.

Some of the observable peaks for the doped samples are at $486 \mathrm{~nm}, 378 \mathrm{~nm}, 342 \mathrm{~nm}$ and $303 \mathrm{~nm}$, which might be attributed to transitions from ground state ${ }^{7} \mathrm{~F}_{6}$ to the higher excited levels, namely, ${ }^{5} \mathrm{D}_{4},\left({ }^{5} \mathrm{G}_{6},{ }^{5} \mathrm{D}_{3}\right),\left({ }^{5} \mathrm{~L}_{7,8}{ }^{5} \mathrm{G}_{3}\right)$, and $4 \mathrm{f}^{8} \rightarrow 4 \mathrm{f}^{7}$ $5 \mathrm{~d}^{1}$ of $\mathrm{Tb}^{3+}$ ions respectively. ${ }^{50}$ The optical direct band gap $\left(E_{\mathrm{g}}\right)$ values of the $\mathrm{LiMgBO}_{3}: x \mathrm{~Tb}^{3+}(x=0,0.01,0.04$ and 0.06$)$ compounds were estimated from the DRS spectra by using the Kubelka-Munk function, the detailed procedure for which is given in Text-S2 (ESI $\dagger)^{51}$ Accordingly, the band gap of all compositions was calculated as given in Table S1 (ESI $\dagger$ ) whereas the representative Kubelka-Munk plot for one composition $\left(\mathrm{LiMgBO}_{3}: 0.06 \mathrm{~Tb}^{3+}\right)$ is shown in Fig. 6 . The band gap of the un-doped $\mathrm{LiMgBO}_{3}$ was found to be $6.3 \mathrm{eV}$, indicating it to be a good insulator which is one of the most desirable properties for a TL material. ${ }^{52}$ It is worth mentioning that, this

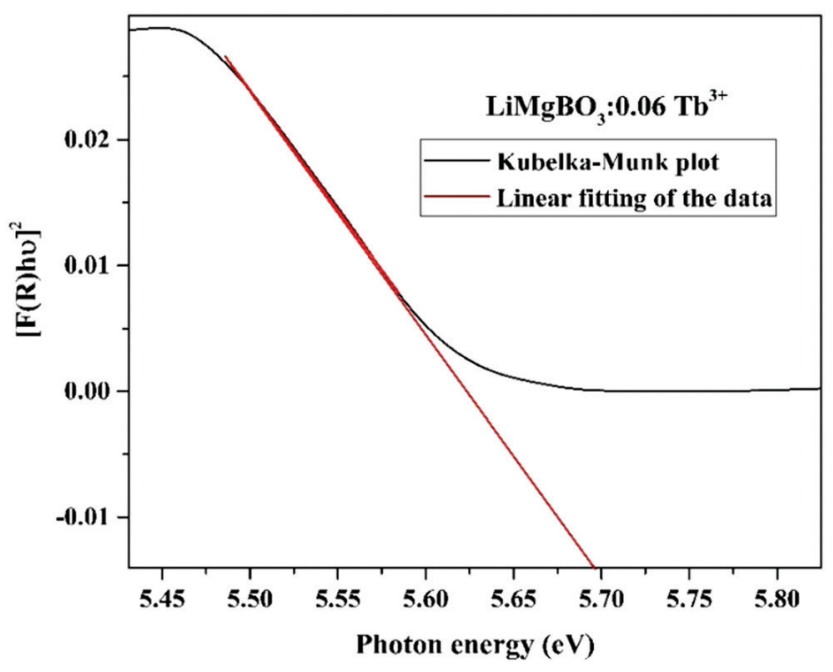

Fig. 6 Band gap determination of $\mathrm{LiMgBO}_{3}: 0.06 \mathrm{~Tb}^{3+}$ using KubelkaMunk plot. feature of the title compound may also find potential applications as a deep UV NLO material. It was also observed that, as the concentration of the $\mathrm{Tb}^{3+}$ ion was increased from $x=0$ to $x=0.06$ the band gap also decreased significantly. In the case of $\mathrm{LiMgBO}_{3}: 0.06 \mathrm{~Tb}^{3+}$ the band gap was found to be $5.69 \mathrm{eV}$, which almost matches with the $\mathrm{Dy}^{3+}$ doped $\mathrm{LiMgBO}_{3} \cdot{ }^{53}$ However, the calculated band gap by ab initio techniques in previous literature reported shows a discrepancy with respect to the presently reported values. ${ }^{32}$ The electronic band structure calculation there revealed that the valence band (VB) was dominated by $\mathrm{O}$ '2p' orbitals with some weak B '2p' orbital contribution and only a small amount of $\mathrm{Li}$ ' $2 \mathrm{~s}$ ' and $\mathrm{Mg}$ ' $3 \mathrm{~s}$ ' orbital contributions. The conduction band (CB) was mainly composed of B ' $2 \mathrm{p}$ ' and $\mathrm{O}$ '2p' orbitals with only small $\mathrm{Li}$ and $\mathrm{Mg}$ orbital contributions. Remarkably, hybridization between B '2p' and $\mathrm{O}$ '2p' orbitals occurred through B-O bonding. ${ }^{32}$ Here, the potential replacement of $\mathrm{Mg}^{2+}$ by $\mathrm{Tb}^{3+}$ in the $\mathrm{LiMgBO}_{3}$ lattice (as discussed in Section 3.1.3) might have formed a hybridization between valence $(5 \mathrm{~d} / 4 \mathrm{f})$ orbitals and the valence $\mathrm{O}$ ' $2 \mathrm{p}$ ' orbital to form a mid-band bap state above the Fermi level similar to as shown earlier where $\mathrm{Mn}^{2+}$ replaced $\mathrm{Li}^{+}$in the same $\mathrm{LiMgBO}_{3}$ lattice. ${ }^{32}$ In the present scenario, the $\mathrm{Tb}^{3+}$ doping in the $\mathrm{LiMgBO}_{3}$ lowers the band gap as a function of concentration. Similar observations were also reported by other researchers. ${ }^{54-56}$

3.1.3 Photoluminescence (PL) studies. Fig. 7 shows the recorded room temperature PL excitation and emission spectra of the $\mathrm{LiMgBO}_{3}: \mathrm{Tb}^{3+}$ phosphor. All the excitation spectra were recorded at an emission wavelength of $547 \mathrm{~nm}$, which consists of multiple peaks viz. at $235 \mathrm{~nm}, 245 \mathrm{~nm}, 263 \mathrm{~nm}, 278 \mathrm{~nm}$, $285 \mathrm{~nm}, 304 \mathrm{~nm}, 322 \mathrm{~nm}$, and $342 \mathrm{~nm}$, respectively.

There are different possibilities for the excitation of $\mathrm{Tb}^{3+}$ ions, which are (i) direct excitation of $\mathrm{Tb}^{3+}$ ions through $\mathrm{f}-\mathrm{f}$ transition and f-d transition, (ii) charge transfer transition (CT), and (iii) excitation through defect assisted energy transfer. ${ }^{57}$ The excitation spectra of all the compounds showed intense peaks at around $235 \mathrm{~nm}$ which can be attributed to the charge transfer transition from the 'p' orbital of oxygen to the vacant ' $f$ ' orbital of $\mathrm{Tb}^{3+}$, while the peak at $245 \mathrm{~nm}$ can be attributed to the spin allowed $\mathrm{f}-\mathrm{d}$ transition

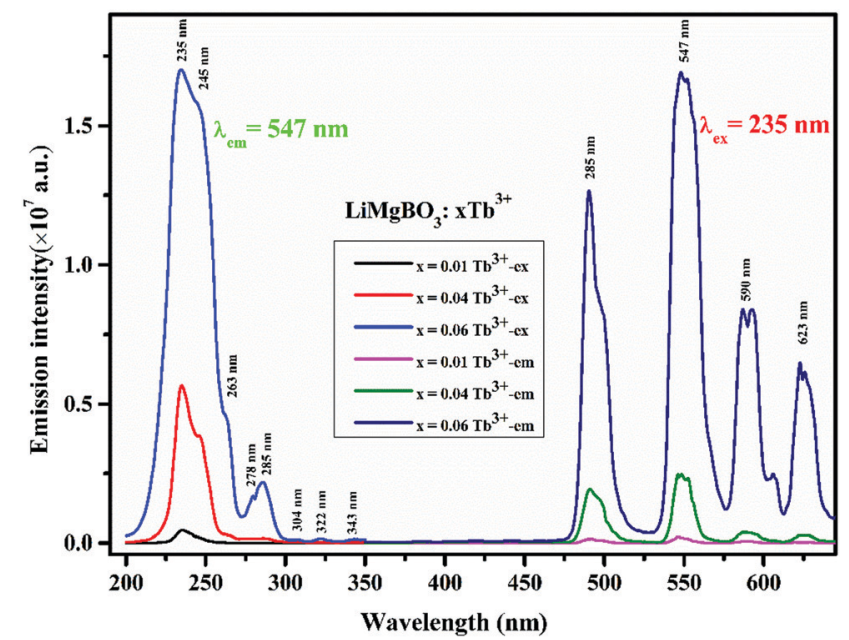

Fig. $7 \mathrm{PL}$ excitation and emission spectra of $\mathrm{LiMgBO}_{3}: \mathrm{Th}^{3+}$ samples (unirradiated). 


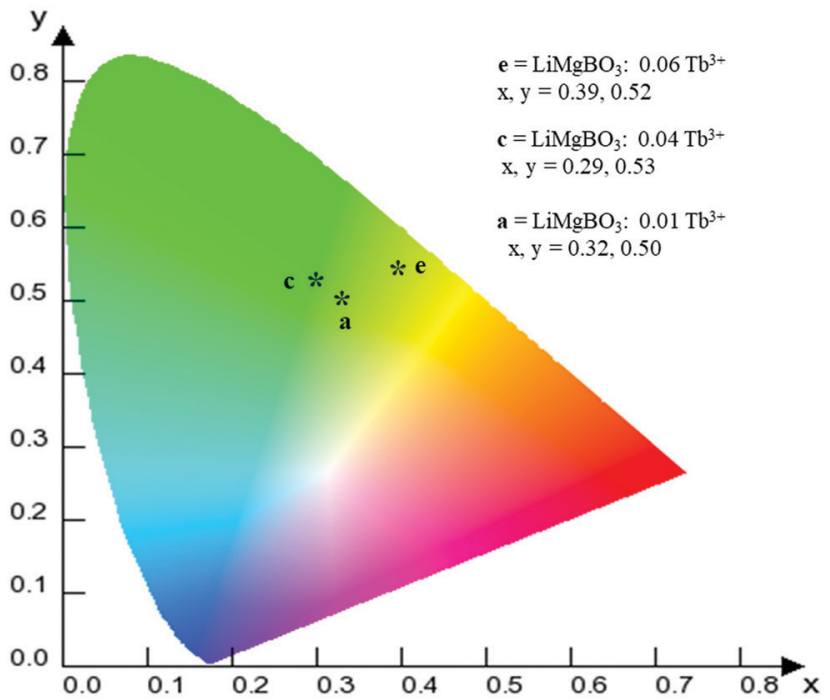

Fig. $8 \mathrm{CIE}$ color coordinate diagram of the $\mathrm{LiMgBO}_{3}: \mathrm{XTb}^{3+}$ phosphor.

of the $\mathrm{Tb}^{3+}$ ion. $^{58}$ Feeble excitation bands at 285, 304, 322, and $340 \mathrm{~nm}$ can be assigned to ${ }^{7} \mathrm{~F}_{6} \rightarrow{ }^{9} \mathrm{E},{ }^{5} \mathrm{~F}_{5},{ }^{5} \mathrm{H}_{6}$ and ${ }^{5} \mathrm{H}_{7}$ respectively. ${ }^{59,60}$ All the emission spectra were recorded at the $235 \mathrm{~nm}$ excitation wavelength, which showed four strong and characteristic emission lines of the $\mathrm{Tb}^{3+}$ ion, viz. 489, 547, 590 and $623 \mathrm{~nm}$ which were attributed to the ${ }^{5} \mathrm{D}_{4} \rightarrow{ }^{7} \mathrm{~F}_{6},{ }^{5} \mathrm{D}_{4} \rightarrow{ }^{7} \mathrm{~F}_{5},{ }^{5} \mathrm{D}_{4} \rightarrow$ ${ }^{7} \mathrm{~F}_{4}$ and ${ }^{5} \mathrm{D}_{4} \rightarrow{ }^{7} \mathrm{~F}_{3}$ transitions, respectively. The PL emission intensity was highest for the $547 \mathrm{~nm}$ excitation band for all the compounds, which can be attributed to the magnetic dipole transition (MDT) of the $\mathrm{Tb}^{3+}$, and such transitions are least affected by the crystal field strength. On the other hand, the emission band at $489 \mathrm{~nm}$ was attributed to the electric dipole transition (EDT) of $\mathrm{Tb}^{3+}$, which is sensitive to local structure. The $\mathrm{PL}$ emission intensity was found to be highest at $x=0.06 \mathrm{~Tb}^{3+}$. The calculated CIE color coordinate of the title compound, as shown in Fig. 8, clearly indicated that it is also a potential green emitting phosphor that could be highly useful in phosphor converted LEDs, and which also reveals the multifunctional nature of the material.
Photoluminescence lifetime measurements were carried out in order to investigate the local surroundings of the $\mathrm{Tb}^{3+}$ ions and the number of $\mathrm{Tb}^{3+}$ components existing in different lattice environments. The lifetime measurements were carried out at $235 \mathrm{~nm}$ excitation and $545 \mathrm{~nm}$ emission wavelengths. It was observed that the decay curves as shown in Fig. 9 were best fitted by the following the bi-exponential equation:

$$
I(t)=A_{1} \exp \left(-\frac{t}{\tau_{1}}\right)+A_{2} \exp \left(-\frac{t}{\tau_{2}}\right)
$$

where $I(t)=$ intensity, $\tau_{1}$ and $\tau_{2}$ are the respective lifetime values of the two different $\mathrm{Tb}^{3+}$ components, while $A_{1}$ and $A_{2}$ are relative weights. The relative percentage of these two components was calculated using the following formula:

$$
\% \text { of species } n=\left[\frac{\left(A_{n} \times \tau_{n}\right)}{\sum_{n=1,2} A_{n} \times \tau_{n}}\right] \times 100
$$

The lifetime values of the un-irradiated $\mathrm{LiMgBO}_{3}: \mathrm{Tb}^{3+}$ compounds, as given in Table 2 , indicate that the $\mathrm{Tb}^{3+}$ ions have two different local structures. Either $\mathrm{Tb}^{3+}$ ions exist in two different lattice sites or they may exist in a similar lattice site but with different defect surroundings. The difference in ionic radii between $\mathrm{Mg}^{2+}[(0.72 \AA),(\mathrm{VI})]$ and $\mathrm{Tb}^{3+}[(0.92 \AA),(\mathrm{VI})]$ is greater compared with that between $\mathrm{Li}^{+}[(0.76 \AA),(\mathrm{VI})]$ and $\mathrm{Tb}^{3+}$ and thus $\mathrm{Tb}^{3+}$ ions are more likely to go to the $\mathrm{Li}^{+}$site. However, there will be a charge difference of ' +2 ' and hence there will be creation of new negatively charged cationic vacancies required for the charge balance. These defects may induce distortion into the matrix and may affect the neighboring lattice sites significantly. Thus, there will be an interplay of two factors which will play an important role in deciding the distribution of $\mathrm{Tb}^{3+}$ ions among the two different lattice sites: the higher charge difference at the $\mathrm{Li}^{+}$-site and the size difference at the $\mathrm{Mg}^{2+}$-site. The crystal structure of $\mathrm{LiMgBO}_{3}$ showed that, there are two different $\mathrm{Li}^{+}$sites and one $\mathrm{Mg}^{2+}$ site, and all of them have a five-coordinated environment. The five coordinated
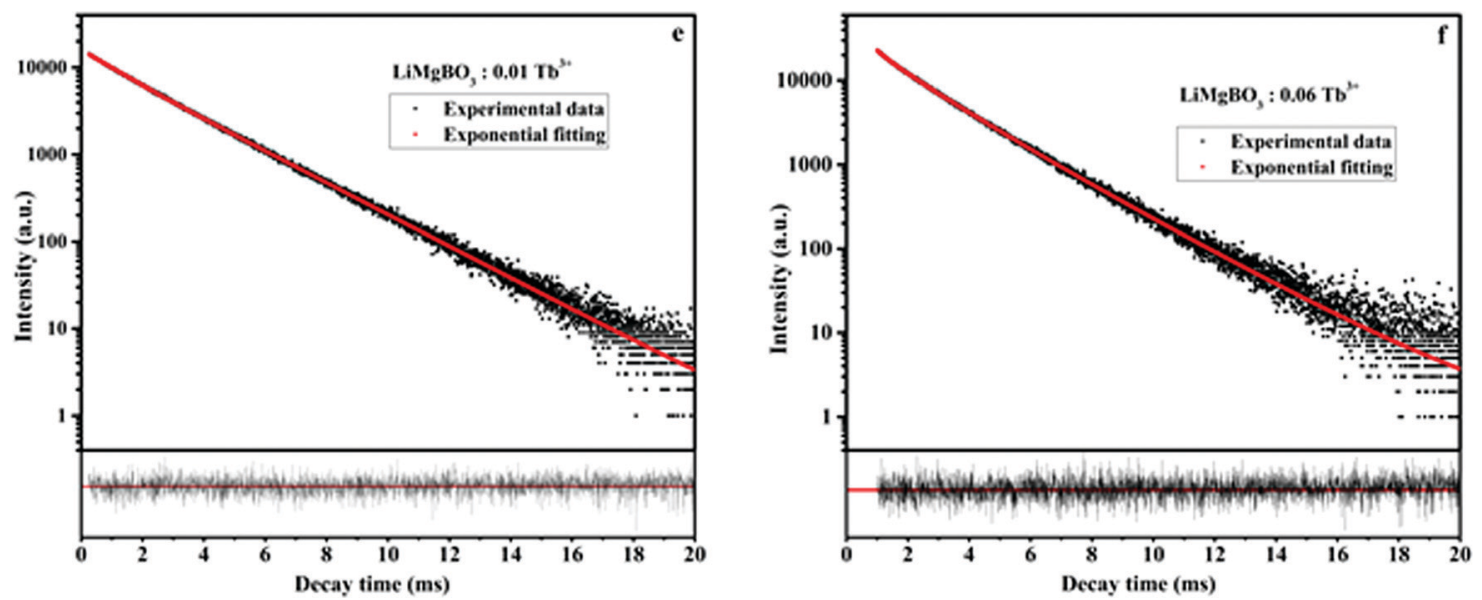

Fig. 9 Lifetime plot of un-irradiated LiMgBO $3: x \mathrm{~Tb}^{3+}(\mathrm{e}: x=0.01, \mathrm{f}: x=0.06)$ samples. 
Table 2 PL lifetime data of un-irradiated $\mathrm{LiMgBO}_{3}: \mathrm{Th}^{3+}$

\begin{tabular}{lllll}
\hline $\mathrm{LiMgBO}_{3}: \mathrm{Tb}^{3+}$ & $\begin{array}{l}\text { Value of } \\
\tau_{1}(\mathrm{~ms})\end{array}$ & $\begin{array}{l}\text { Contribution } \\
(\%)\end{array}$ & $\begin{array}{l}\text { Value of } \\
\tau_{2}(\mathrm{~ms})\end{array}$ & $\begin{array}{l}\text { Contribution } \\
(\%)\end{array}$ \\
\hline$x=0.01$ & 1.136 & 8 & 2.389 & 92 \\
$x=0.04$ & 2.041 & 85 & 2.814 & 15 \\
$x=0.06$ & 2.301 & 84 & 2.679 & 16
\end{tabular}

$\mathrm{Mg}^{2+}$ sites roughly form trigonal bipyramidal polyhedra. However, the Li sites have a distorted trigonal bipyramidal configuration since both the Li atoms are five-coordinated by four close $\mathrm{O}$ atoms and one distant $\mathrm{O}$ atom. Since $\mathrm{f}-\mathrm{f}$ transitions of $\mathrm{Tb}^{3+}$ are spin- and parity-forbidden and become allowed in an asymmetric environment, the short lifetime value can be attributed to $\mathrm{Tb}^{3+}$ occupying these distorted Li sites. Further, the charge difference of ' +2 ' will create additional defect centers which will induce more distortion. The fact that the fraction of the short-lived component is very low $(\leq 10 \%)$ suggests that $\mathrm{Tb}^{3+}$ does not prefer to occupy the $\mathrm{Li}^{+}$site. On the contrary, the long-lived component with a higher percentage must be due to $\mathrm{Tb}^{3+}$ ions at the more symmetric $\mathrm{Mg}^{2+}$ site. However, the higher intensity of the MD line at $545 \mathrm{~nm}$ in the emission spectra for all the compounds suggests that the $\mathrm{Tb}^{3+}$ ions are preferably occupying the more symmetrical $\mathrm{Mg}^{2+}$ site, since the ED line is only allowed in the case of a more asymmetric environment. Therefore, the two different lifetime values might be due to two different $\mathrm{Tb}^{3+}$ ion situated at crystallographically identical $\mathrm{Mg}^{2+}$ sites but with different defect centers surrounding them. Some defect centers may act as an electron trap state which increases the lifetime value while others provide a nonradiative pathways to the excited state and thus reduce the lifetime value. ${ }^{61}$ Moreover, the distance of such defect centers from the lattice sites also exerts an impact on the excited states. Thus, the short-lived component might be close to a defect center while the long-lived component might be far from such defect centers. ${ }^{62}$ It is important to note that the short life time value makes a low contribution in samples where the concentration of the $\mathrm{Tb}^{3+}$ dopant is low, while it is the reverse when the concentration of $\mathrm{Tb}^{3+}$ ion is increased. Therefore, it is plausible to infer that, at a low dopant level, the defect centers are present in very low amounts since the amount of charge imbalance in the matrix is low. However, with an increase in the concentration of $\mathrm{Tb}^{3+}$ ions, the overall number of defect centers created in the matrix must be increased due to higher amount of charge imbalance which results in the higher percentage of short-lived species. It might be noted that the values of the short-lived and long-lived components are also different at higher dopant levels, which might be because of the different location of such defect centers with respect to the $\mathrm{Tb}^{3+}$ ion.

\subsection{Application of $\mathrm{LiMgBO}_{3}: \mathrm{Tb}^{3+}$ as personnel neutron dosimeter}

3.2.1 Thermoluminescence (TL) studies. In order to investigate the applicability of the title material for personnel neutron dosimetry, first the TL dosimetric characterization of $\mathrm{LiMgBO}_{3}: x \mathrm{~Tb}^{3+}\left(x=0,0.01,0.02,0.03,0.04\right.$ and $\left.0.06 \mathrm{~Tb}^{3+}\right)$ was carried out by irradiating equal amounts $(2 \mathrm{mg})$ of samples with

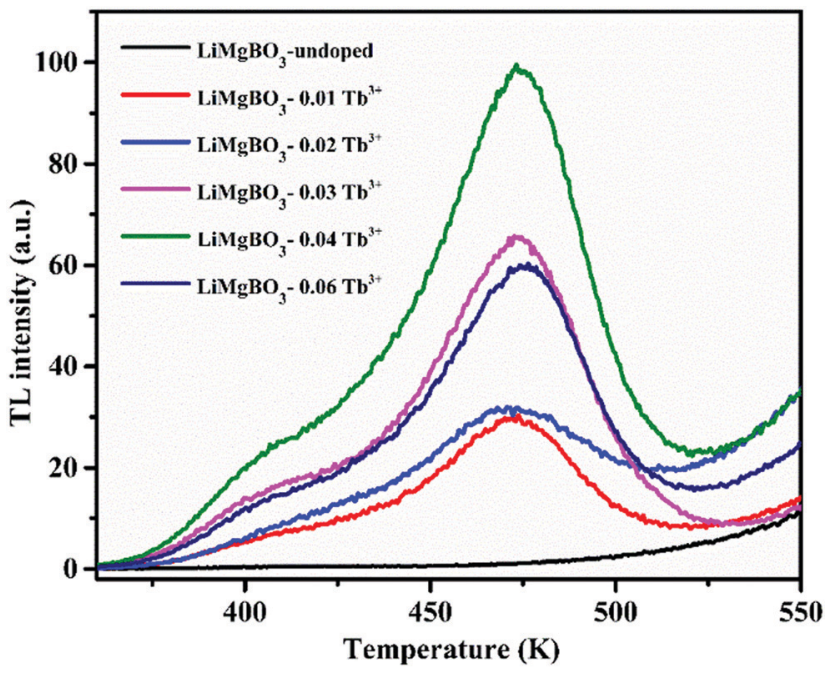

Fig. $10 \mathrm{TL}$ glow curve patterns of different compositions of $\mathrm{LiMgBO}_{3}: \mathrm{Tb}^{3+}$.

thermal neutrons from the ${ }^{241} \mathrm{Am}-\mathrm{Be}$ neutron source in the Standard Thermal Assembly in Graphite facility whose details may be found elsewhere. ${ }^{63}$ The total neutron dose delivered to all the samples was $10 \mathrm{mSv}$ and TL measurements were carried out post $5 \mathrm{~h}$ of the removal of the samples from the irradiation chamber. TL measurements were carried out at the heating rate of $4 \mathrm{~K} \mathrm{~s}^{-1}$ and the TL emission data were recorded within the 330-600 nm wavelength region. Fig. 10 shows the observed TL glow curve patterns of the samples which are similar for all the compositions, indicating the good reproducibility of the material preparation. The TL glow curve consists of two peaks viz. at $408 \mathrm{~K}$ and $475 \mathrm{~K}$ which have been considered here as the shoulder peak and the dosimetry peak, respectively. However, the un-doped $\mathrm{LiMgBO}_{3}$ did not show any TL glow peak upon neutron irradiation, which highlights the importance of the dopant ion in inducing the TL response in the material.

Fig. 10 also indicated that the TL intensity gradually increased as the concentration of dopant ion is increased from $0.01 \mathrm{~Tb}^{3+}$ to $0.04 \mathrm{~Tb}^{3+}$ where it reaches maximum and begins to decrease on further increase in the concentration until 0.06 $\mathrm{Tb}^{3+}$, as also shown in Fig. S4 (ESI $\dagger$ ). The above observation may be explained as follows: the irradiation of $\mathrm{LiMgBO}_{3}: x \mathrm{~Tb}^{3+}$ with neutrons resulted in the creation of high linear energy transfer (LET) charged particles followed by the formation of electron-hole pairs which were trapped by the respective trap centres present in the matrix. These electrons and holes upon heating during TL measurements recombined at luminescence centres resulting in radiative photons which further excited the nearby $\mathrm{Tb}^{3+}$ ions giving rise to $\mathrm{TL}$ emission. As the concentration of $\mathrm{Tb}^{3+}$ increased, a greater number of $\mathrm{Tb}^{3+}$ ions were excited which led to the increase in the TL intensity subsequently. However, after the peak dopant concentration $\left(0.04 \mathrm{~Tb}^{3+}\right)$, the overall TL intensity was found to decrease due to the concentration quenching phenomenon. ${ }^{64,65}$ Therefore, $0.04 \mathrm{~Tb}^{3+}$ was found to be the optimum dopant concentration in terms of the maximum TL intensity among the studied compositions, and further neutron dosimetry studies were carried out using this 
composition unless otherwise specified. Further, the neutron induced TL sensitivities of the presently developed $\mathrm{LiMgBO}_{3}$ : $0.04 \mathrm{~Tb}^{3+}$ and the commercially available LiF:Mg,Ti dosimeter were compared. Equal amounts of both dosimeters were subjected to a neutron dose of $21.7 \mathrm{mSv}$ and the TL glow curves were recorded after 15 days of storage which almost nullified the effect of the initial fading of the TL signal of both the materials. A total of eight samples were irradiated: four samples each from the $\mathrm{LiMgBO}_{3}: 0.04 \mathrm{~Tb}^{3+}$ and LiF:Mg,Ti dosimeters. Two samples from each dosimeter were irradiated by being kept inside a $1 \mathrm{~mm}$ thick cadmium (Cd) disc which will absorb all the thermal neutrons and will allow the gamma radiation emanating from ${ }^{241} \mathrm{Am}-\mathrm{Be}$ neutron source to pass through. Thus, these samples will have a TL response $\left(R_{\gamma}\right)$ mainly for gamma radiation whereas the other two samples from each dosimeter were irradiated without the Cd box, which will have a response for both neutron- and gammaradiation $\left(R_{n+\gamma}\right)$. Therefore, the net neutron response was obtained by subtracting the average values of $R_{\gamma}$ from those of $R_{n+\gamma}$. The comparison between the TL glow curves of LiMg$\mathrm{BO}_{3}: 0.04 \mathrm{~Tb}^{3+}$ and LiF:Mg,Ti is given in Fig. 11. It shows that the TL glow curve of the presently developed material is very simple compared with the complex and multipeak pattern of ${ }^{6 /}$ ${ }^{7} \mathrm{LiF}: \mathrm{Mg}$,Ti. The most important observation to note here is that the neutron induced net TL sensitivity of $\mathrm{LiMgBO}_{3}: 0.04 \mathrm{~Tb}^{3+}$ is about 2.2 times higher than that of LiF:Mg,Ti when the area

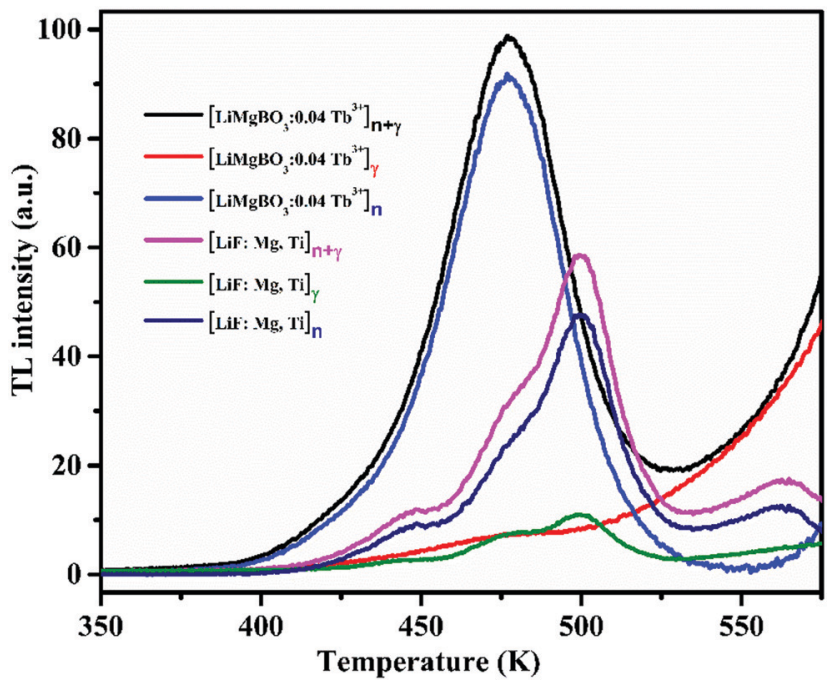

Fig. 11 Comparison of $\mathrm{TL}$ glow curves of $\mathrm{LiMgBO}_{3}: 0.04 \mathrm{~Tb}^{3+}$ and LiF:Mg,Ti. under the TL glow curve of both the dosimeters was compared. The high neutron sensitivity of $\mathrm{LiMgBO}_{3}: 0.04 \mathrm{~Tb}^{3+}$ compared with LiF:Mg,Ti may partly be attributed to the presence of both $\mathrm{Li}$ and $\mathrm{B}$ in the $\mathrm{LiMgBO}_{3}: 0.04 \mathrm{~Tb}^{3+}$, which create a larger number of effective carriers responsible for the TL sensitivity upon interaction with neutrons compared with that of LiF:Mg,Ti where only $\mathrm{Li}$ is present in the host matrix. On the other hand, it is well known that the neutron field is mostly associated with gamma radiation in workplace environments. Therefore, a comparison of the TL response of both the dosimeters was also done by irradiating with gamma rays. To do this, both the samples were irradiated with a $2000 \mathrm{mGy}$ gamma dose from a ${ }^{60} \mathrm{Co}$ source and the corresponding TL glow curves are shown in Fig. S5 (ESI $\dagger$ ). It is shown that $\mathrm{LiMgBO}_{3}: 0.04 \mathrm{~Tb}^{3+}$ has two broad TL glow peaks along with an additional small peak lying at $408 \mathrm{~K}, 463 \mathrm{~K}$ and $360 \mathrm{~K}$, respectively. The comparisons of the TL sensitivity have been summarized in Table 3 where the TL intensity was taken as the area under the full TL glow peak of both the dosimeters. It was observed that the TL intensity of $\mathrm{LiMgBO}_{3}: 0.04 \mathrm{~Tb}^{3+}$ is almost half compared with LiF:Mg,Ti for the same gamma dose. However, the most important observation here is that the ratio of $\mathrm{TL}$ response per unit neutron dose to the TL response per unit gamma dose is about 4.5 times greater for $\mathrm{LiMgBO}_{3}: 0.04 \mathrm{~Tb}^{3+}$ than that of LiF:Mg,Ti. This suggests that $\mathrm{LiMgBO}_{3}: 0.04 \mathrm{~Tb}^{3+}$ has a greater $n / \gamma$ dose discrimination capability in comparison to LiF:Mg,Ti dosimeter which is highly advantageous in mixed field environments.

One of the most important properties for any TL material to be applicable for personnel neutron dosimetry is that its TL response should be linear up to a neutron dose of $100 \mathrm{mSv}$, as per ISO-21909. ${ }^{66}$ In order to carry out the study, equal weights of the annealed powder samples (2 mg) of $\mathrm{LiMgBO}_{3}: 0.04 \mathrm{~Tb}^{3+}$ were taken in stainless cups and spread uniformly over the surface. The samples were kept for irradiation at the central cavity of the STAG facility. ${ }^{63}$ The dose rate for thermal neutrons at the irradiation location was $0.23 \mathrm{mSv} \mathrm{h}^{-1}$ on the date of the experiment, which was calculated by multiplying the thermal neutron fluence rate and the corresponding conversion factor as given in ISO-8529-3. ${ }^{67}$ Initially all the samples were kept at the irradiation chamber together and then removed at different time intervals and subsequently they were kept inside a lighttight box. The TL readout of the stored samples was carried out after almost the same latency period such that the fading of the TL signal does not have any effect on the TL intensity. The corresponding TL glow curves of the samples for different

Table 3 Neutron and gamma induced TL sensitivity comparison of $\mathrm{LiMgBO}_{3}: 0.04 \mathrm{~Tb}^{3+}$ and $\mathrm{LiF}: \mathrm{Mg}, \mathrm{Ti}$

\begin{tabular}{|c|c|c|c|c|}
\hline \multirow[b]{2}{*}{ Data type } & \multicolumn{2}{|l|}{$\mathrm{LiMgBO}_{3}: \mathrm{Tb}^{3+}$} & \multicolumn{2}{|l|}{ LiF:Mg,Ti } \\
\hline & $\begin{array}{l}\text { Neutron dose } \\
(21.7 \mathrm{mSv})\end{array}$ & $\begin{array}{l}\text { Gamma dose } \\
(2000 \text { mGy) }\end{array}$ & $\begin{array}{l}\text { Neutron dose } \\
(21.7 \mathrm{mSv})\end{array}$ & $\begin{array}{l}\text { Gamma dose } \\
\text { (2000 mGy) }\end{array}$ \\
\hline TL intensity $\left[\mathrm{AUC} \times 10^{5} \mathrm{mg}^{-1}\right]$ & $(6.82 \pm 0.12)$ & $(11.7 \pm 0.73)$ & $(3.08 \pm 0.04)$ & $(23.7 \pm 1.42)$ \\
\hline TL intensity $\left[\right.$ AUC $\times 10^{4} \mathrm{mg}^{-1}$ per dose $]$ & $(3.14 \pm 0.06)$ & $(0.06 \pm 0.004)$ & $(1.42 \pm 0.02)$ & $(0.12 \pm 0.01)$ \\
\hline TL intensity for neutron $\left[\mathrm{LiMgBO}_{3}: \mathrm{Tb}^{3+}\right] /[\mathrm{LiF}: \mathrm{Mg}, \mathrm{Ti}]$ & $(2.2 \pm 0.05)$ & & & \\
\hline TL intensity for gamma $\left[\mathrm{LiMgBO}_{3}: \mathrm{Tb}^{3+}\right] /[\mathrm{LiF}: \mathrm{Mg}, \mathrm{Ti}]$ & $(0.5 \pm 0.04)$ & & & \\
\hline TL intensity [neutron dose (mSv)]/[gamma dose (mGy)] & $(54 \pm 3)$ & $(12 \pm 1)$ & & \\
\hline
\end{tabular}




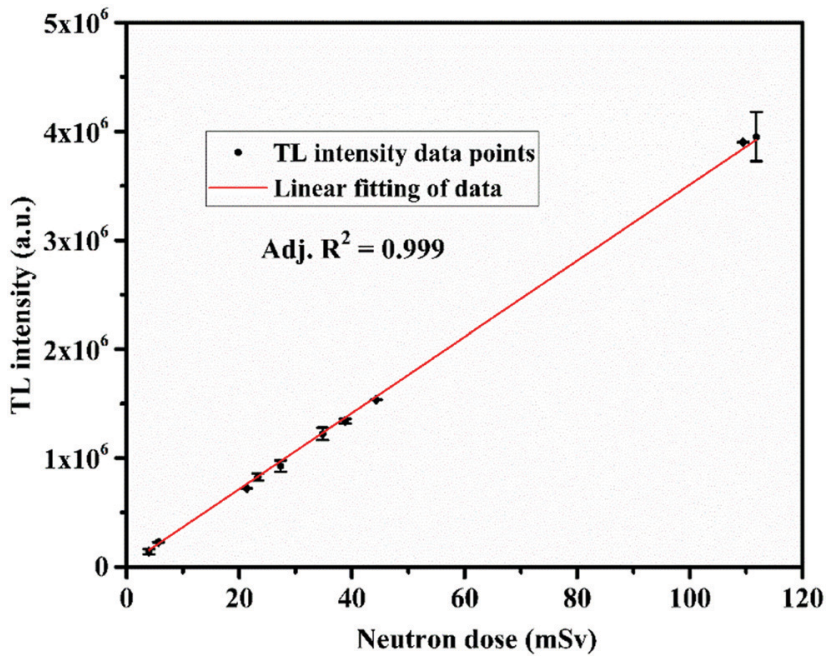

Fig. $12 \mathrm{TL}$ versus neutron dose linearity of the $\mathrm{LiMgBO}_{3}: 0.04 \mathrm{~Tb}^{3+}$ phosphor.

neutron doses are shown in Fig. S6 (ESI $\dagger)$. The important feature observed from the glow curves is that the temperature corresponding to the maximum TL intensity $\left(T_{\mathrm{m}}\right)$ remained unchanged even at a very high neutron dose of $105 \mathrm{mSv}$. This indicates that the TL process is obeying first order kinetics. However, detailed analysis will follow later. Fig. 12 depicts the neutron dose linearity curve where the area under the dosimetric glow peak was taken as the TL response.

It is clearly seen that the TL response up to the neutron dose of $105 \mathrm{mSv}$ showed excellent linearity with an adjusted $R^{2}=$ 0.999 which satisfies the ISO-21909 criteria. The minimum detectable dose (MDD) is another highly important parameter for a TL based neutron dosimeter which signifies the ability of the material to measure the lowest possible neutron dose. Based on the variations in the background, the MDD values for both the $\mathrm{LiMgBO}_{3}: 0.04 \mathrm{~Tb}^{3+}$ and $\mathrm{LiF}: \mathrm{Mg}$,Ti dosimeters were estimated as three times the standard deviation $(\sigma)$ of the background TL signal. Four samples each from both the $\mathrm{LiMgBO}_{3}$ : $0.04 \mathrm{~Tb}^{3+}$ and LiF:Mg,Ti dosimeters were taken. The background TL readings of each un-irradiated sample were recorded. The mean and standard deviations were evaluated for both dosimeters. The neutron irradiated net TL intensity was obtained from the corresponding TL measurements (with respect to Fig. 11 as was mentioned earlier in the neutron sensitivity comparison of both the dosimeters). The MDD was found to be about $5 \mu \mathrm{Sv}$ and $6 \mu \mathrm{Sv}$ for $\mathrm{LiMgBO}_{3}: 0.04 \mathrm{~Tb}^{3+}$ and LiF:Mg,Ti respectively, which is shown in Table S2 (ESI $\dagger$ ). This suggests that the MDD of the presently developed material is comparable is to the existing dosimeter. Another most important and desirable feature is that the fading of the neutron induced TL signal must be negligibly small for its practical use in dosimetry applications. According to ISO-21909, the fading must be less than $10 \%$ for a storage period of 90 days. ${ }^{66}$ To investigate such a stringent performance of the developed $\mathrm{LiMgBO}_{3}: 0.04 \mathrm{~Tb}^{3+}$, equal amounts of samples were irradiated for same neutron dose of $10 \mathrm{mSv}$. After removal, all the samples were kept in a

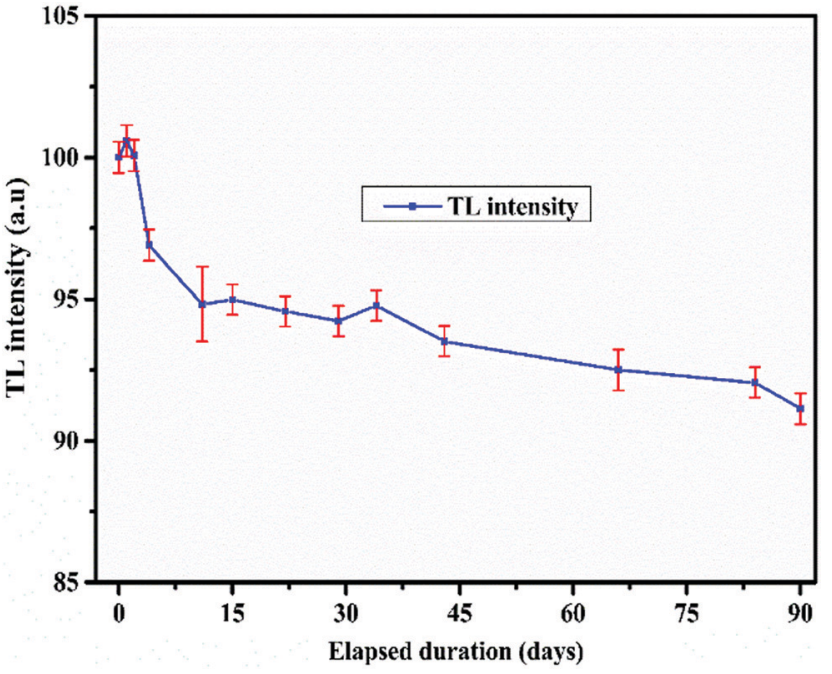

Fig. 13 Fading study of $\mathrm{LiMgBO}_{3}: 0.04 \mathrm{~Tb}^{3+}$

light-tight box in a plastic cover. The TL readings were recorded at different time intervals spanning up to 90 days from the date of the removal from the irradiation chamber, as shown in Fig. 13.

The area under the dosimetric TL glow peak was taken as the signal and each data point is the average of three different samples. It was observed that about $6 \%$ of the TL signal fades within a storage period of the first 10 days and the remaining 3\% signal fades over a span of 80 days, leading to maximum fading of about $9 \%$ in 90 days which satisfies the ISO-21909 criteria.

\subsection{Understanding TL behaviour}

3.3.1 Neutron irradiated PL and EPR investigations. To find a correlation between the TL and PL data, the compounds were irradiated with thermal neutrons and then the room temperature PL spectra were recorded as shown in Fig. 14. It was observed that the order of PL intensity with respect to the different concentrations of $\mathrm{Tb}^{3+}$ ions in the $\mathrm{LiMgBO}_{3}$ host matched exactly with that of the intensity obtained in the TL measurements.

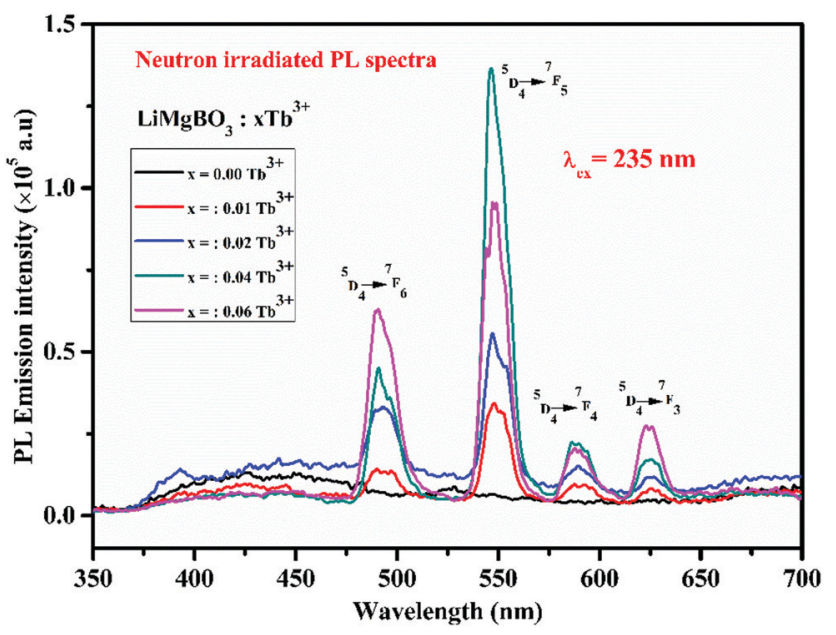

Fig. $14 \mathrm{PL}$ emission spectra of neutron irradiated $\mathrm{LiMgBO}_{3}: \mathrm{XTb}^{3+}$ samples. 
The PL intensity of the $547 \mathrm{~nm}$ peak increases from $x=0.01$ $\mathrm{Tb}^{3+}$ to $x=0.04 \mathrm{~Tb}^{3+}$ and then decreases on further increases in the dopant concentration $\left(x=0.06 \mathrm{~Tb}^{3+}\right)$. This might also be due to the concentration quenching phenomenon as described earlier in TL. ${ }^{64,65}$ However, instead of heating in the TL study, UV light acts here as the excitation source because of which the generated electron and hole pairs followed by neutron irradiation, get de-trapped and recombined similar to TL which in turn excites the $\mathrm{Tb}^{3+}$ ions resulting in $\mathrm{PL}$ emission. Among the neutron irradiated samples, highest PL intensity was obtained for the $\mathrm{LiMgBO}_{3}: 0.04 \mathrm{~Tb}^{3+}$ sample. Further, to study the effect of neutron- and gamma-irradiation on the PL emission property, the $\mathrm{LiMgBO}_{3}: x \mathrm{~Tb}^{3+}(x=0.04$ and 0.06$)$ samples were irradiated with both neutron- and gamma-radiation. Interestingly, it was observed that the PL intensity of both the neutron- and gamma-irradiated samples decreased significantly from that of the un-irradiated ones as shown in Fig. 15.

Moreover, the extent of decrease in the PL intensity is greater in the case of neutron-irradiated samples than that for the gamma-irradiated ones. This phenomenon may be explained as follows: as the present compound consists of both $\mathrm{Li}$ and $\mathrm{B}$ atoms, both of which have a very high absorption cross section for thermal neutrons; in turn, high-LET charged particles were generated leading to the creation of several defect centres which exert a severe impact on the matrix and might lead to the pathways favouring the non-radiative processes during the emission from the excited states to ground states of $\mathrm{Tb}^{3+}$. On the other hand, the interaction of gamma radiation with the matrix creates only secondary electrons, which are relatively low LET particles, and thereby the extent of impact is less and there is a lower creation of defect centres, thereby the decrease in PL intensity is low compared with that by neutron irradiation. However, there was no observable change in the wavelength of the emission lines for both the irradiated samples. The lifetime properties of these irradiated compounds were also studied. It is worth mentioning here that the defect centres created in the irradiated samples were mainly due to radicals, while those for un-irradiated compounds were mostly related to various lattice site vacancies. Thus, the lifetime values of the former must be different from those of the latter ones. In irradiated samples it was also found that the decay profiles as shown in Fig. 16 followed bi-exponential behaviour and two lifetime values were obtained, which were completely different from the respective un-irradiated samples.

It was observed from Table 4 that the short-lived component has a lower value than that of the un-irradiated samples, and the fraction of the long-lived component is always higher. Interestingly, the neutron irradiated TL study revealed that there were two different glow peaks at two different temperatures, which indicated that there are two different types of trap centres. Thus, the two different lifetime values have been linked to these two trap states. The long-lived component with the higher contribution (\%) is linked to the deep trap state which is responsible for the TL glow curve at higher temperatures $\left(T_{\mathrm{m}}=475 \mathrm{~K}\right)$, while the short-lived component with the lower contribution (\%) is linked to a shallow trap state which is responsible for the TL glow peak at low temperatures $\left(T_{\mathrm{m}}=408 \mathrm{~K}\right)$. Further, the relative contributions in terms of the area under the two different TL glow peaks of $\mathrm{LiMgBO}_{3}: 0.04 \mathrm{~Tb}^{3+}$ were also estimated after irradiating with different neutron doses as shown in Table 5 . Remarkably, it was found that the relative contributions of both the low- and high-temperature TL glow peaks matched very well with those of the short-lived and long-lived components, respectively, which again justifies the correlation of lifetime values to the different TL glow peaks. Therefore, the PL lifetime measurement of the neutron irradiated samples can be a great tool in order to explain the generation of various TL glow peaks and their relative contributions towards the total TL intensity. On the other hand, the lifetime values for neutron- and gammairradiated samples were also compared as shown in Table S3 (ESI $\dagger$ ). It was observed that the lifetime values were low for neutron irradiated samples compared with the gamma irradiated ones. Further the fraction of the long-lived component is relatively higher compared with the short-lived component when the samples were irradiated with neutrons. On the other hand, for gamma irradiated samples, such a difference between the two components is comparatively low. Lastly, in order to provide more concrete evidence about the evolution of different defect
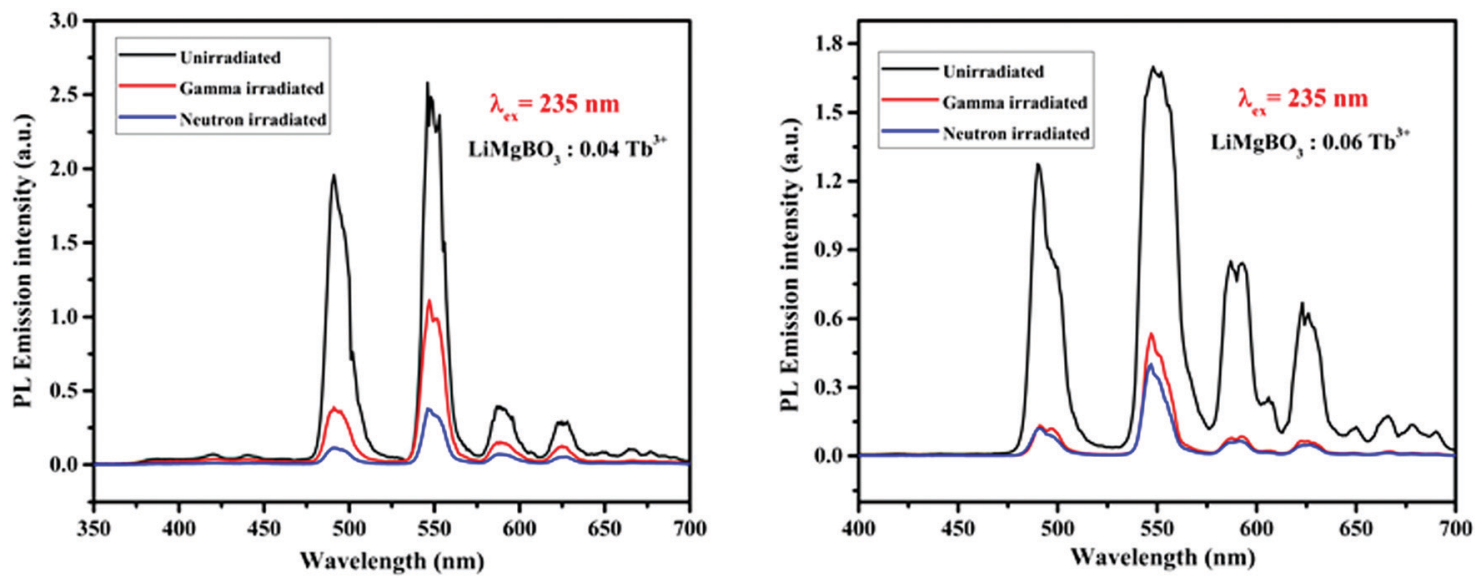

Fig. 15 Comparison of PL emission intensity for un-irradiated, gamma- and neutron-irradiated $\mathrm{LiMgBO}_{3}: \mathrm{Xb}^{3+}(x=0.04$ and 0.06$)$. 

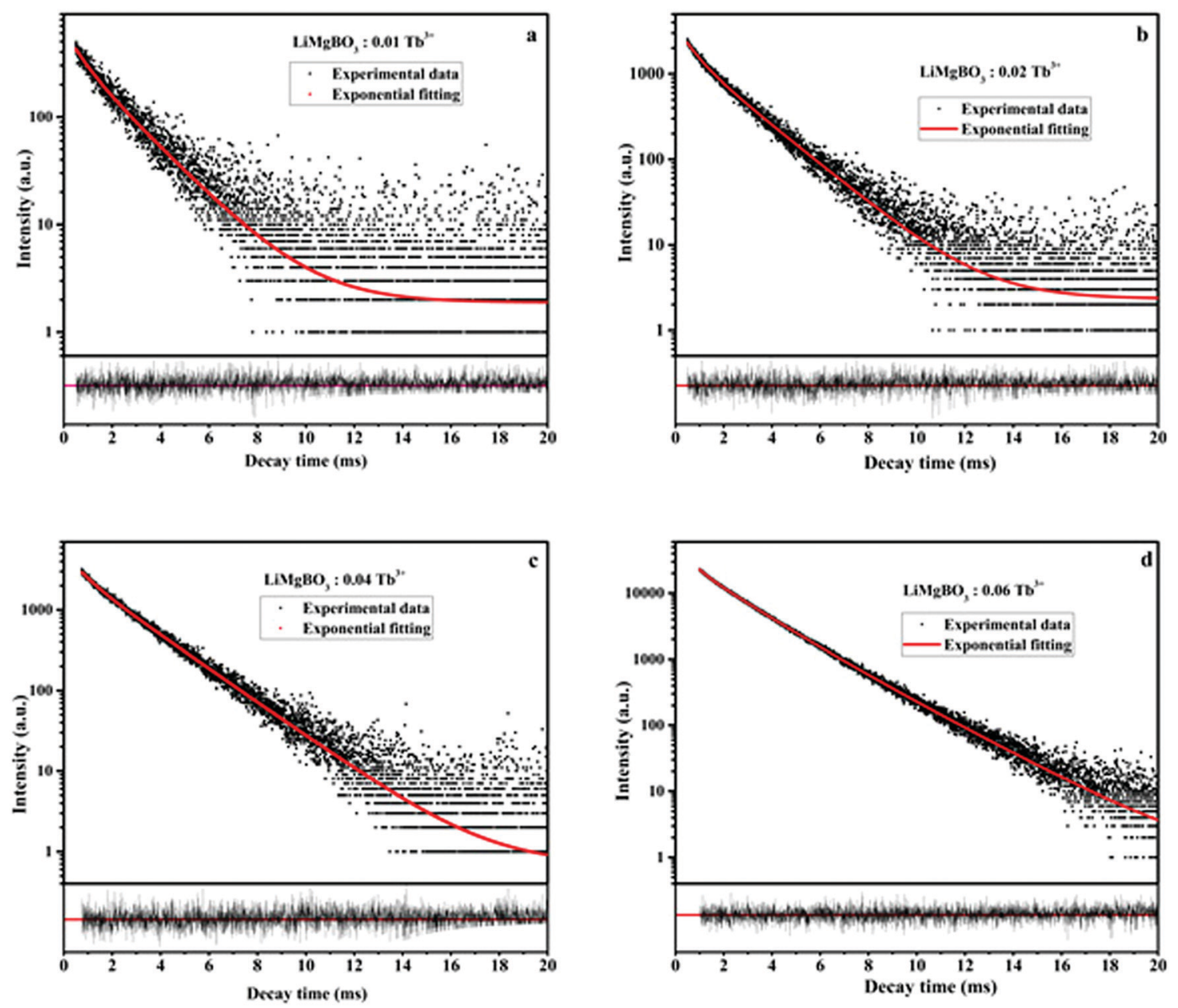

Fig. 16 Lifetime plot of neutron irradiated $\mathrm{LiMgBO}_{3}: \mathrm{TTb}^{3+}(\mathrm{a}-\mathrm{d}: x=0.01,0.02,0.04 \& 0.06)$ samples

Table 4 PL lifetime data of neutron irradiated $\mathrm{LiMgBO}_{3}: \mathrm{xTb}^{3+}$

\begin{tabular}{llrll}
\hline $\mathrm{LiMgBO}_{3}: \mathrm{Tb}^{3+}$ & $\begin{array}{l}\text { Value of } \\
\tau_{1}(\mathrm{~ms})\end{array}$ & $\begin{array}{l}\text { Contribution } \\
(\%)\end{array}$ & $\begin{array}{l}\text { Value of } \\
\tau_{2}(\mathrm{~ms})\end{array}$ & $\begin{array}{l}\text { Contribution } \\
(\%)\end{array}$ \\
\hline$x=0.01$ & 0.592 & 9 & 1.892 & 90 \\
$x=0.02$ & 0.546 & 11 & 1.877 & 89 \\
$x=0.04$ & 0.623 & 7 & 2.075 & 93 \\
$x=0.06$ & 0.870 & 13 & 2.091 & 87
\end{tabular}

centers, the room temperature EPR study of neutron- and gamma-irradiated $\mathrm{LiMgBO}_{3}: 0.04 \mathrm{~Tb}^{3+}$ was carried out. The unirradiated samples did not show any EPR signals which indicated the absence of any paramagnetic centers prior to irradiation. Fig. 17 shows the EPR spectra of gamma- and neutron-irradiated $\mathrm{LiMgBO}_{3}: 0.04 \mathrm{~Tb}^{3+}$ samples.

From the spectra, two well-resolved resonance signals were found at $g=2.01$ and $g=2.04$ respectively. Referring to the literature these signals were attributed to the $\left[\mathrm{BO}_{3}\right]^{2-}$ and $\left[\mathrm{O}_{2}\right]^{-}$ radicals, respectively, both of which act as possible hole trap centers. ${ }^{68-70}$ Thermoluminescence (TL) emission was mainly caused by the radiative recombination of holes and electrons which are thermally released from the corresponding trap centers. In the present case, that the existence of the electrons
Table $5 \mathrm{TL}$ glow peak contributions of $\mathrm{LiMgBO}_{3}: 0.04 \mathrm{~Tb}^{3+}$ for different neutron doses

\begin{tabular}{lll}
\hline $\begin{array}{l}\text { Neutron } \\
\text { dose }(\mathrm{mSv})\end{array}$ & $\begin{array}{l}\text { Contribution (\%) } \\
\text { of the shoulder peak }\end{array}$ & $\begin{array}{l}\text { Contribution (\%) of } \\
\text { the dosimetry peak }\end{array}$ \\
\hline 3.7 & 7 & 93 \\
5.3 & 6 & 94 \\
20.1 & 7 & 93 \\
21.9 & 6 & 94 \\
25.8 & 7 & 93 \\
32.8 & 7 & 93 \\
36.6 & 7 & 93 \\
41.7 & 7 & 93
\end{tabular}

${ }^{a}$ Area under the peak from $350 \mathrm{~K}$ to $425 \mathrm{~K} .{ }^{b}$ Area under the peak from $425 \mathrm{~K}$ to $525 \mathrm{~K}$.

trapped at an anion vacancy $\left[\mathrm{O}_{\mathrm{v}}\right]^{-}$could not be detected may be because of the very low concentration or large line width of the resonance signal. ${ }^{71,72}$ Based on the generation of the above trap centers, a possible mechanism for the generation of TL in $\mathrm{LiMgBO}_{3}: \mathrm{Tb}^{3+}$ has been established. Upon irradiation of the material with neutron- or gamma-radiation, different defect centres viz. $\left[\mathrm{BO}_{3}\right]^{2-}$ and $\left[\mathrm{O}_{2}\right]^{-}$and $\left[\mathrm{O}_{\mathrm{v}}\right]^{-}$were created. When heated during TL readout, the hole trap centre releases holes 


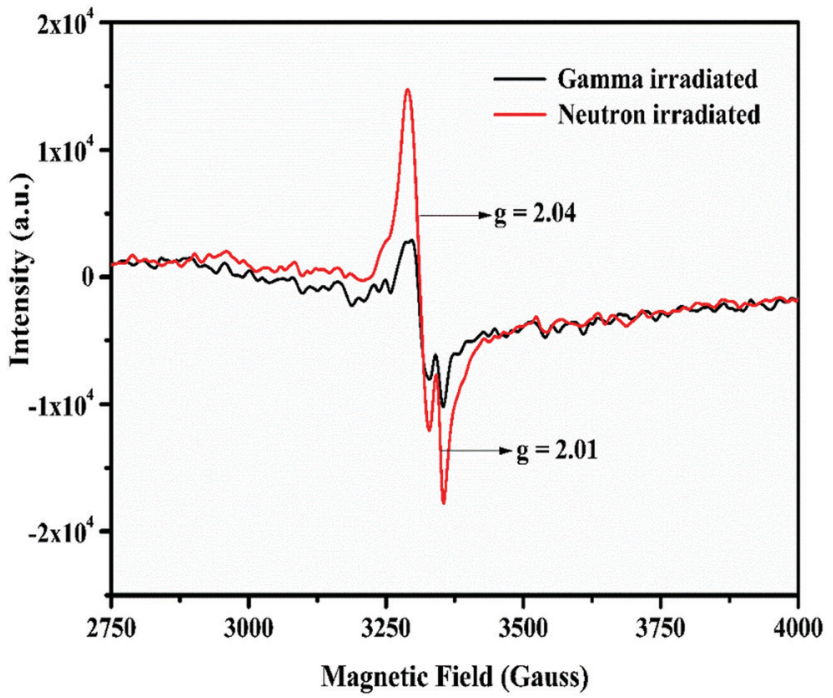

Fig. 17 EPR spectra of neutron- and gamma-irradiated $\mathrm{LiMgBO}_{3}: 0.04 \mathrm{~Tb}^{3+}$ phosphor.

which recombine with the electrons emitted from the electron trap centre, resulting in the emission of radiative photons from the luminescence centres. The energy released here excites the energy levels of the adjacent $\mathrm{Tb}^{3+}$ ions present in the material. The excited $\mathrm{Tb}^{3+}$ ions decay through their characteristic emission of light, giving rise to the resulting TL glow peaks. The mechanism may be given as follows:

$$
\begin{aligned}
& \mathrm{LiMgBO}_{3}: \mathrm{Tb}^{3+} \stackrel{\text { irradiation }}{\longrightarrow} \mathrm{BO}_{3}^{2-}, \mathrm{O}_{2}^{-}, \mathrm{O}_{v}^{-} \\
& \mathrm{O}_{2}^{-} \rightarrow \mathrm{O}_{2}^{2-}+\mathrm{h} \\
& \mathrm{BO}_{3}^{2-} \rightarrow \mathrm{BO}_{3}^{3-}+\mathrm{h} \\
& \mathrm{O}_{\mathrm{v}}^{-} \rightarrow \mathrm{O}_{\mathrm{v}}+\mathrm{e} \\
& \mathrm{e}+\mathrm{h} \rightarrow[\mathrm{hv}] \stackrel{\mathrm{Tb}^{3+}}{\longrightarrow}\left[\mathrm{Tb}^{3+}\right]^{*} \rightarrow\left[\mathrm{Tb}^{3+}\right]+(h \nu)_{\mathrm{TL}}
\end{aligned}
$$

Another observable feature in Fig. 17 is that the intensity of the EPR signal is greater in the case of the neutron-irradiated sample than it is for the gamma-irradiated one. This might be due to the large thermal neutron absorption cross sections of both Li and B present in the host matrix, which create large numbers of defects compared with the gamma irradiation. Moreover, the EPR intensity at the $g=2.04$ signal being the highest must be responsible for the high temperature TL glow peak, whereas the lower intensity signal at $g=2.01$ may be corelated to the low temperature TL peak. Therefore, the combination of neutron irradiated PL and EPR studies provided lots of valuable and innovative insights which helped to understand the origin of TL glow peaks, their relative intensities, and the underlying TL mechanism of the $\mathrm{LiMgBO}_{3}: \mathrm{Tb}^{3+}$ phosphor.

\subsection{Determination of TL based kinetic parameters}

To understand the kinetics of the neutron irradiated TL glow curve of the $\mathrm{LiMgBO}_{3}: \mathrm{Tb}^{3+}$ phosphor it was very important to estimate various kinetic parameters viz. the activation energy $(E)$, frequency factor $(s)$ and order of kinetics $(b)$. Therefore, two different methods viz. the peak shape and variable heating rate were applied.

Peak shape method. The method was first proposed by Chen, Text S3 (ESI $\dagger$ ), which uses different temperature parameters of the TL glow peak to determine a symmetry factor $\left(\mu_{\mathrm{g}}\right)$ based on the which the order of kinetics $(b)$ can be obtained. ${ }^{73}$ For the first and second order peaks, the value is 0.42 and 0.52 respectively whereas for other $\mu_{\mathrm{g}}$ values the order can be obtained from Chen's plot. Once $b$ is known, $E$ and $s$ can be determined by empirical equations, as given in Text S3 (ESI $\dagger$ ). The kinetic parameters of the dosimetric glow peak of $\mathrm{LiMgBO}_{3}$ : $0.04 \mathrm{~Tb}^{3+}$ for different heating rates, viz. $0.5,1,3,5$ and $7 \mathrm{~K} \mathrm{~s}^{-1}$, were estimated following the above method, and are given in Table S4 (ESI $\dagger$ ). It was observed that the order of kinetics $(b)$ of the dosimetric glow peak is 1.1 for all the heating rates, which means that the TL kinetics are first order. The average values of $E$ and $s$ were found to be $(0.92 \pm 0.01) \mathrm{eV}$ and $(1.4 \pm 0.2) \times$ $10^{9} \mathrm{~s}^{-1}$, respectively.

Variable heating rate method. The determination of ' $E$ ' and 's' using this method is dependent upon the position of the TL glow peak maximum $\left(T_{\mathrm{m}}\right)$ with respect to the different heating rates $(\beta)$. The neutron irradiated (dose $=15.6 \mathrm{mSv}$ ) TL glow curves of $\mathrm{LiMgBO}_{3}: \mathrm{Tb}^{3+}$ were recorded for the different heating rates, viz. 0.5, 1, 3, 5 and $7 \mathrm{~K} \mathrm{~s}^{-1}$, as shown in Fig. 18.

It was observed that, the $T_{\mathrm{m}}$ shifted towards higher temperature as the heating rate was increased. This was attributed to the fact that the time spent by the material at a temperature is higher at the lower heating rate than it is at higher heating rates. Therefore, the thermal release at that particular temperature is greater for a low heating rate. However, as the heating rate increases, the time spent is lower, which needs a higher temperature for the same amount of thermal release from the material. This led to the shifting of the TL glow peaks to the higher temperature side. However, the shape of the glow curve was unchanged. Following the relation between $T_{\mathrm{m}}$ and $\beta$ from

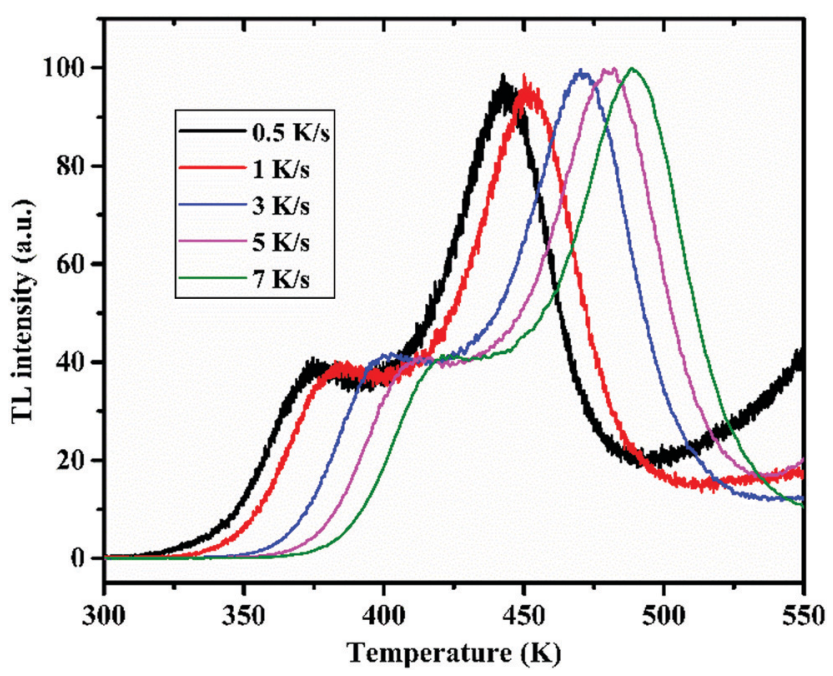

Fig. $18 \mathrm{TL}$ glow curve of $\mathrm{LiMgBO}_{3}: 0.04 \mathrm{~Tb}^{3+}$ for different heating rates. 


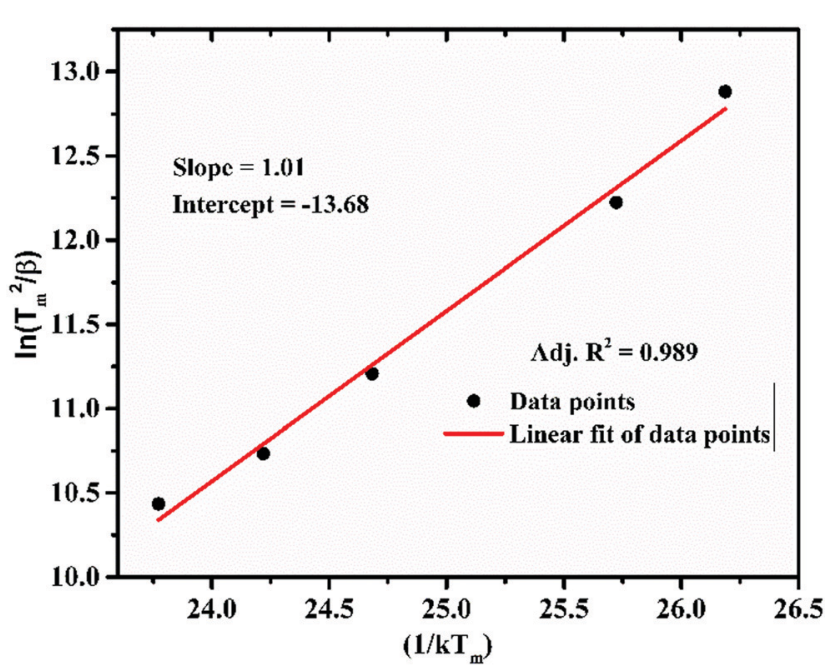

Fig. $19 \ln \left(T_{\mathrm{m}}{ }^{2} / \beta\right)$ versus $\left(1 / k T_{\mathrm{m}}\right)$ plot for $\mathrm{LiMgBO}_{3}: 0.04 \mathrm{~Tb}^{3+}$.

the first derivative of the Randall-Wilkins equation as given in Text-4 (ESI $\dagger$ ), Hoogenstraaten (1958) proposed to estimate the value of ' $E$ ' and ' $s$ ' from the plot of $\ln \left(T_{\mathrm{m}}{ }^{2} / \beta\right)$ against $\left(1 / k T_{\mathrm{m}}\right)$ which gives a straight line whose slope is equal to $E$ and the intercept is equal to $\ln \left(\frac{E}{s k}\right) \cdot{ }^{74,75}$ For $\mathrm{LiMgBO}_{3}: 0.04 \mathrm{~Tb}^{3+}$, the linear fitting of the plot of $\ln \left(T_{\mathrm{m}}{ }^{2} / \beta\right)$ against $\left(1 / k T_{\mathrm{m}}\right)$, as shown in Fig. 19, gives the slope and intercept of 1.01 and -13.68 respectively. The activation energy $(E)$ and frequency factor $(s)$ obtained are $1.01 \mathrm{eV}$ and $1.02 \times 10^{10} \mathrm{~s}^{-1}$, respectively. Further, $E$ and $s$ values were also estimated following the methodology of using two different heating rates $\left(\beta_{1}\right.$ and $\left.\beta_{2}\right)$, proposed by Booth and Bohun as given in Text S5 (ESI $\dagger)^{76,77}$ The results for the $\mathrm{LiMgBO}_{3}: 0.04 \mathrm{~Tb}^{3+}$ are depicted in Table S5 (ESI $\dagger$ ) and show that $E$ varied from 0.92 to $1.02 \mathrm{eV}$ and that $s$ varied between $0.1 \times$ $10^{10}$ and $6.6 \times 10^{10} \mathrm{~s}^{-1}$. The average value for ' $E$ ' and ' $s$ ' was found to be $0.98 \pm 0.04 \mathrm{eV}$ and $(7.1 \pm 4.8) \times 10^{9} \mathrm{~s}^{-1}$ respectively. Therefore, it is found that the activation energy and the frequency factor obtained from the different methods agree very well. The most important conclusion is that the TL kinetics of the material follow a first order relationship as obtained from Chen's peak shape method of analysis, which is also supported by the results obtained from the variation of the TL glow peaks with different neutron doses.

\section{Conclusion}

In summary, a highly efficient and near tissue equivalent LiMgBO ${ }_{3}: \mathrm{Tb}^{3+}$ phosphor has been developed for the potential application in the personnel neutron dosimetry. The DRUV-Vis study proved that it as a wide band gap $(6.3 \mathrm{eV})$ material. PL emission study of the un-irradiated compounds revealed it to be a strong green emitting phosphor and the corresponding lifetime study explained the distribution of $\mathrm{Tb}^{3+}$ in the host matrix. The neutron-irradiated PL lifetime study was remarkably correlated with the origin of different TL glow peaks and their relative contributions. EPR study revealed the generation of different defect centres upon neutron- and gamma-irradiation, based on which the underlying TL mechanism has been established. The neutron induced TL study of $\mathrm{LiMgBO}_{3}: \mathrm{Tb}^{3+}$ showed a simple glow curve compared with the complex pattern of the existing LiF:Mg,Ti dosimeter. On comparison, it was found that the neutron-induced TL sensitivity and the $n / \gamma$ dose discrimination capability of $\mathrm{LiMgBO}_{3}: \mathrm{Tb}^{3+}$ is 2.2 times and 4.5 times higher, respectively, than that of the standard LiF:Mg,Ti dosimeter. Moreover, the presently developed material showed an excellent neutron dose linearity up to $105 \mathrm{mSv}$ and it has less than $10 \%$ fading of the TL signal even up to a 90 day storage period. These features meet the ISO 21909 criteria for its practical applicability as a TL based personnel neutron dosimeter. Therefore, the present work provides a great boost towards the systematic development of new and efficient materials along with the in-depth understanding of dosimetry properties to mitigate the huge scarcity of TL materials for neutron dosimetry applications. It is strongly believed that the presently developed $\mathrm{LiMgBO}_{3}: \mathrm{Tb}^{3+}$ can be a potential alternative to the existing LiF:Mg,Ti dosimeter for personnel neutron dosimetry.

\section{Conflicts of interest}

There are no conflicts to declare.

\section{Acknowledgements}

The authors are highly thankful to Suresh Babu R. M. Director, Health Safety and Environment Group for his support in carrying out these works. Thanks to Fuel Chemistry Division, BARC for the help in recording the SEM and EDS data. Also special thanks to Radiological Standards group, RSS, RSSD, BARC and for providing the standard LiF:Mg,Ti powder and support during the gamma irradiations of the samples in ${ }^{60} \mathrm{Co}$ machine. The work was funded by Bhabha Atomic research Centre (BARC), Department of Atomic Energy, India.

\section{References}

1 F. Daniels, C. Boyd and D. Saunders, Science, 1953, 117, 343-349. 2 S. W. S. McKeever, Thermoluminescence of Solids, Cambridge, UK, 1985.

3 S. Zhang, Z. Song, S. Wang, Z. Wang, F. Wang and Q. Liu, J. Mater. Chem. C, 2020, 8, 4956-4964.

4 T. Lyu and P. Dorenbos, Chem. Mater., 2020, 32, 1192-1209.

5 G. Repettoa, J. L. Zuritaa, M. Roncelb and J. M. Ortega, Aquat. Toxicol., 2015, 158, 88-97.

6 J. F. Fowler, E. Shuttleworth, V. Svarcer, J. T. White and C. J. Karzmark, Nature, 1965, 207, 997-998.

7 J. R. Cameron, F. Daniels, N. M. Johnson and G. Kenney, Science, 1961, 134, 233.

8 K. Ayyangar, A. R. Lakshmanan, B. Chandra and K. Ramadas, Phys. Med. Biol., 1974, 19, 665-676.

9 M. Budzanowski, P. Bilski, T. Niewiadomski, B. Brugkhardtanf and E. Piesch, Radiat. Prot. Dosim., 1993, 47, 419-423.

10 A. R. Lakshmanan, Nucl. Tracks, 1982, 6, 59-78. 
11 Y. S. Horowitch and B. B. Shachar, Radiat. Prot. Dosim., 1988, 23, 401-404.

12 M. Budzanowski and B. Burghhardt, Radiat. Meas., 1995, 24, 445-448.

13 Y. S. Horowitch, Radiat. Meas., 1993, 47, 135-141.

14 J. I. Lee, J. S. Yang, J. L. Kim, A. S. Pradhan, J. D. Lee, K. S. Chung and H. S. Choe, Appl. Phys. Lett., 2006, 89, 094110.

15 Y. Y. Liang and Z. H. Liu, J. Mater. Res., 2016, 31, 1433-1439.

16 A. C. Fernandes, M. Osvay, J. P. Santos, V. Holovey and M. Ignatovych, Radiat. Meas., 2008, 43, 476-479.

17 S. İflazoğlu, A. Yilmaz, V. E. Kafadar and A. N. Yazici, J. Therm. Anal. Calorim., 2018, 133, 1327-1333.

18 S. İflazoğlua, A. Yilmaz, V. E. Kafadar, M. Topaksu and A. N. Yazici, Appl. Radiat. Isot., 2019, 147, 91-98.

19 O. Annalakshmi, M. T. Jose, B. Venkatraman and G. Amarendra, Mater. Res. Bull., 2014, 50, 494-498.

20 I. Kawamura, H. Kawamoto, Y. Fujimoto, M. Koshimizu, G. Okada, Y. Koba, R. Ogawara, T. Yanagida and K. Asai, J. Ceram. Soc. Jpn., 2019, 127, 663-668.

21 L. Wu, J. C. Sun, Y. Zhang, S. F. Jin, Y. F. Kong and J. J. Xu, Inorg. Chem., 2010, 49, 2715-2720.

22 C. T. Chen, Y. Wang, B. Wu, K. Wu, W. Zeng and L. Yu, Nature, 1995, 373, 322-324.

23 S. Wang, N. Ye and G. Zou, Inorg. Chem., 2014, 53, 2742-2748.

24 P. Becker, Adv. Mater., 1998, 10, 979-992.

25 W. Hongping, Y. Hongwei, Z. Yang, X. Hou, X. Su, S. Pan, K. R. Poeppelmeier and J. M. Rondinelli, J. Am. Chem. Soc., 2013, 135(11), 4215-4218.

26 Z. Jiyou, Z. Ya, H. Shruti, Z. Weiren, W. Jun and B. Jakoah, Chem. Mater., 2020, 32, 882-888.

27 H. A. Lehmann, H. Schadow and H. J. Papenfuss, Z. Anorg. Allg. Chem., 1962, 314, 159-166.

28 K. H. Prasad, S. Subramanian, T. N. Sairam, G. Amarendra, E. S. Srinadhu and N. Satyanarayana, J. Alloys Compd., 2017, 718, 459-470.

29 L. Zhijuan, M. Fuwang, Z. Xinguo and Z. Liya, J. Lumin., 2014, 151, 47-51.

30 S. Tamilarasan, S. Laha, S. Natarajan and J. Gopalakrishnan, Eur. J. Inorg. Chem., 2016, 288-293.

31 A. K. Bedyal, A. K. Kunti, S. G. Menon, V. Kumar and H. C. Swart, J. Alloys Compd., 2020, 830, 154622.

32 L. Wu, Y. Baia, L. Wua, H. Yia, X. Zhanga, L. Zhanga, Y. Konga, Y. Zhangb and J. Xu, Dalton Trans., 2018, 47, 13094-13105.

33 S. N. Menon, S. Kadam, S. Watanabe, T. K. G. Rao, M. S. Kulkarni and D. A. R. Babu, J. Lumin., 2015, 167, 140-155.

34 M. M. Yerpude, V. Chopra, N. S. Dhoble, R. M. Kadam, A. R. Krupski and S. J. Dhoble, Luminescence, 2019, 1, 1-12.

35 M. Sen, R. Shukla, V. Sathian, M. S. Kulkarni and A. K. Tyagi, Ceram. Int., 2020, 46, 20236-20242.

36 D. I. Shahare, B. T. Deshmuk, S. V. Moharil, S. M. Dhopte, P. L. Muthal and V. K. Kondawa, Phys. Status Solidi, 1994, 141, 329-334.

37 L. C. Oliveira, E. G. Yukihara and O. Baffa, Sci. Rep., 2016, 6, 24348.

38 D. Wang, B. A. Doull, L. C. Oliveira and E. G. Yukihara, $R S C$ Adv., 2013, 3, 26127.
39 X. Huang, J. Liang, S. Rtimi, B. Devakumar and Z. Zhang, Chem. Eng. J., 2021, 405, 126950.

40 S. Wang, B. Devakumar, Q. Sun, J. Liang, L. Sun and X. Huang, J. Mater. Chem. C, 2020, 8, 4408-4420.

41 L. Sun, B. Devakumar, J. Liang, S. Wang, Q. Suna and X. Huang, J. Mater. Chem. C, 2019, 7, 10471-10480.

42 P. P. Kulkarni, K. H. Gavhane, M. S. Bhadane, V. N. Bhoraskar, S. S. Dahiwale and S. D. Dhole, Mater. Adv., 2020, 1, 1113-1124.

43 M. Prokić and E. G. Yukihara, Radiat. Meas., 2008, 43, 463-466.

44 J. Rodriguez-Carvajal, A Program for Rietveld, Profile Matching and Integrated Intensity Refinements for X-ray and Neutron Data, Version 1.6, Laboratoire Leon Brillouin, Gif sur Yvette, France, 2001.

45 A. Belkebir, P. Tarte, A. Rulmont and B. Gilbert, New J. Chem., 1996, 20, 311-316.

46 A. Rulmont and M. Almou, Spectrochim. Acta, 1989, 45A, 603-610.

47 Z. Wang, M. Zhang, S. L. Pan, Y. Wang, H. Zhang and Z. Chen, Dalton Trans., 2014, 43, 2828-2834.

48 L. Wu, J. C. Sun, Y. Zhang, S. F. Jin, Y. F. Kong and J. J. Xu, Inorg. Chem., 2010, 49, 2715-2720.

49 R. Ma, L. Shao, K. Wu, M. Lao, M. Shui, C. Chen, D. Wang, N. Long, Y. Ren and J. Shu, Ceram. Int., 2013, 39, 9309-9317.

50 A. Dehelean, S. Rada, M. Zagrai, R. Suciu and C. Molnar, Anal. Lett., 2020, 54, 88-97.

51 A. E. Morales, E. S. Mora and U. Pal, Rev. Mex. Fis., 2007, 53, 18-22.

52 V. Kortov, Radiat. Meas., 2007, 42, 576-581.

53 A. K. Bedyal, V. Kumar, R. Prakash, O. M. Ntwaeaborwa and H. C. Swart, Appl. Surf. Sci., 2015, 329, 40-46.

54 A. D. Sontakke, K. Biswas and K. Annapurna, J. Lumin., 2009, 129, 1347-1355.

55 A. Wagh, Y. Raviprakash, V. Upadhyaya and S. D. Kamath, Spectrochim. Acta, Part A, 2015, 151, 696-706.

56 H. Guo, Y. Wang, Y. Gong, H. Yin, Z. Mo, Y. Tang and L. Chi, J. Alloys Compd., 2016, 686, 635-640.

57 V. S. Kavitha, R. R. Krishnan, R. S. Sreedharan, K. Suresh, C. K. Jayasankar and V. P. M. Pillai, J. Alloys Compd., 2019, 788, 429-445.

58 S. Xu, L. Panlai, Z. Wang, T. Li, Q. Bai, J. Sun and Z. Yanga, J. Mater. Chem. C, 2015, 3, 9112-9121.

59 W. Carnall, P. Fields and K. Rajnak, Int. J. Chem. Phys., 1968, 49, 4447.

60 J. Chrysochoos and A. Evers, Spectrosc. Lett., 1973, 6, 203-216.

61 P. Das, N. Pathak, B. Sanyal, S. Dash and R. M. Kadam, J. Alloys Compd., 2019, 810, 151906.

62 S. K. Gupta, N. Pathak and R. M. Kadam, J. Lumin., 2016, 169, 106-114.

63 A. Kannan, P. S. Rao, R. N. Sachadev, V. V. Shaha, D. Sharma and P. K. Srivastava, BARC/I992/E/O48, https://inis.iaea.org/ collection/NCLCollectionStore/Public/24/067/24067417.pdf?r= $1 \& \mathrm{r}=1,1992$.

64 D. L. Dexter and J. H. Schulman, J. Chem. Phys., 1954, 22, 1063. 
65 P. D. Johnson and F. E. Williams, J. Chem. Phys., 1950, 18, 1477. 66 ISO 21909, First edition, International Standard, Passive personal neutron dosimeters: Performance and test requirements, 2005 (E).

67 ISO 8529-3, Calibration of area and personal dosimeters and determination of their response as a function of neutron energy and angle of incidence, 1998 (E).

68 N. K. Porwal, R. M. Kadam, T. K. Seshagiri, V. Natarajan, A. R. Dhobale and A. G. Page, Radiat. Meas., 2005, 40, 69-75.

69 M. Anitha, M. Mohapatra, R. M. Kadam, T. K. Seshagiri, A. K. Tyagi and V. Natarajan, J. Mater. Res., 2006, (21), 1117-1123.
70 C. Naccache, P. Meriaudeau, M. Che and A. J. Tench, Trans. Faraday Soc., 1971, 67, 506.

71 X. Koschnick, J.-M. Spaeth and S. R. Eachus, J. Phys.: Condens. Matter, 1992, 4, 3015-3029.

72 T. H. Pawlik, V. Dierolf and J.-M. Spaeth, J. Phys.: Condens. Matter, 1997, 9, 1857-1862.

73 R. Chen, J. Electrochem., 1969, 116, 1254-1257.

74 R. Chen, J. Mater. Sci., 1976, 11, 1521-1541.

75 W. Hoogenstraaten, Philips Res. Rep., 1958, 13, 515-562.

76 A. H. Booth, Can. J. Chem., 1954, 32, 214.

77 A. Bohun, Czech. J. Phys., 1954, 4, 91. 